\title{
WestVirginiaUniversity
}

THE RESEARCH REPOSITORY @ WVU

Graduate Theses, Dissertations, and Problem Reports

2001

\section{Seasonal plasticity of A15 dopaminergic neurons in the ewe}

Van Lee Adams

West Virginia University

Follow this and additional works at: https://researchrepository.wvu.edu/etd

\section{Recommended Citation}

Adams, Van Lee, "Seasonal plasticity of A15 dopaminergic neurons in the ewe" (2001). Graduate Theses, Dissertations, and Problem Reports. 1282.

https://researchrepository.wvu.edu/etd/1282

This Thesis is protected by copyright and/or related rights. It has been brought to you by the The Research Repository @ WVU with permission from the rights-holder(s). You are free to use this Thesis in any way that is permitted by the copyright and related rights legislation that applies to your use. For other uses you must obtain permission from the rights-holder(s) directly, unless additional rights are indicated by a Creative Commons license in the record and/ or on the work itself. This Thesis has been accepted for inclusion in WVU Graduate Theses, Dissertations, and Problem Reports collection by an authorized administrator of The Research Repository @ WVU. For more information, please contact researchrepository@mail.wvu.edu. 
Seasonal Plasticity of A15 Dopaminergic Neurons in the Ewe

\author{
Van L. Adams \\ Thesis submitted to the \\ School of Medicine \\ at West Virginia University \\ in partial fulfillment of the requirements \\ for the degree of
}
Master of Science
in
Physiology

\title{
Robert L. Goodman, Ph.D., Chair \\ John M. Connors, Ph.D. \\ Adrienne K. Salm, Ph.D.
}

Department of Physiology

\author{
Morgantown, West Virginia \\ 2001
}

Keywords: Neuronal plasticity, seasonality, sheep, dopamine; LH, thyroid hormones, estradiol 


\title{
ABSTRACT \\ Seasonal Plasticity of A15 Dopaminergic Neurons in the Ewe
}

\author{
Van L. Adams
}

In the ewe, anestrus is caused by increased sensitivity to $E_{2}$ negative feedback that is mediated by A15 dopaminergic neurons that are only responsive to $E_{2}$ in anestrus. Experiment 1, tested the hypothesis that synaptic input on A15 neurons varies with season by examining synapsin-positive close contacts on A15 cells using immunofluorescence and confocal microscopy. The number of contacts on dendrites, but not somata, increased during anestrus. There were also corresponding changes in dendritic morphology including an increase in dendritic length, surface area, and number of bifurcations. Because thyroid hormones are necessary for the transition to anestrus, we next examined the role of T4 in these changes. An increase in dendrite mean length was found in thyroid-intact and T4-treated thyroidectomized ewes compared to thyroidectomized animals. Thus, seasonal changes in input to and, dendritic morphology of, A15 neurons may play a role in seasonal breeding, with the latter dependent on T4. 


\section{ACKNOWLEDGMENTS}

I am grateful to many people for help with the completion of this thesis. First, I would like to thank my advisor Dr. Robert Goodman for being an excellent teacher, mentor, and editor. I would also like to thank the other members of my committee, Dr. John Connors and Dr. Adrienne Salm for all of their instruction. Thanks must go to the following people: graduate student Steve Hardy for always answering my questions, Dr. Christina McManus for all of the help with this thesis, advice, and providing a lot of reference material, Dr. Miroslav Valent for assistance in the lab, and Jeff Altemus for assistance with the confocal microscope and neurolucida. Finally, I would like to thank the members of my family: Van A. Adams and Marrilyn Adams, Elizabeth, Leslie, Catherine, and Autumn. 


\section{TABLE OF CONTENTS}

Page

Acknowledgements

iii

List of Tables

$\mathrm{V}$

List of Figures vi vi

Chapter One: Introduction 1

Chapter Two: Review of Literature 4

$\begin{array}{ll}\text { Chapter Three: Methods and Materials } & 29\end{array}$

Chapter Four: Results 35

$\begin{array}{ll}\text { Chapter Five: Discussion } & 60\end{array}$

$\begin{array}{ll}\text { Literature Cited } & 70\end{array}$

$\begin{array}{ll}\text { Curriculum Vita } & 79\end{array}$ 


\section{LIST OF TABLES}

Page

Table 1: Treatment Groups for Animals in Experiment 2 


\section{LIST OF FIGURES}

Figure 1. Timeline of Treatments Given to Animals in Experiment 234

Figure 2. Volumes of Cell Body Breeding vs. Non-Breeding Season 40

Figure 3. Mean Length of Dendrites Breeding vs. Non-Breeding Season 40

Figure 4. Mean Number of Bifurcations in Dendrites Breeding Vs. Non-Breeding Season

Figure 5. Mean Surface Area of Dendrites Breeding vs. Non-Breeding Season

Figure 6. Number of Primary Dendrites on Neurons in Breeding Vs. Non-Breeding Season

Figure 7. Number of Total Terminals on Neurons in the Breeding vs. Non-Breeding Season

Figure 8. Number of Terminals on Dendrites during Breeding vs.

Non-Breeding Season

Figure 9. Number of Terminals on Cell Body in Breeding vs.

Non-Breeding Season

Figure 10. Terminal Density on Cell Body in Breeding vs.

Non-Breeding Season

Figure 11. Terminal Density on Dendrite in Breeding vs. Non-Breeding Season

Figure 12. The Average of the Total Number of Endings of Dendrites

That Were Counted at the Top and Bottom of the z-stacks

Figure 13. The Average of the Number of Endings of Dendrites when

Subtracting the Number taken from the Top Section from the Number Taken from the Bottom Section of the z-stacks

Figure 14. Cell Body Surface Area in Thyroid and Estrogen Treated Animals

Figure 15. Mean Length of Dendrites in Thyroid and Estrogen Treated Animals

Figure 16. Mean Surface Area of Dendrites in Thyroid and Estrogen Treated Animals

Figure 17. Mean Number of Bifurcations in Thyroid and Estrogen

Treated Animals

Figure 18. Mean Number of Primary Dendrites per Neuron in Thyroid And Estrogen Treated Animals

Figure 19. Total Number of Contacts on Neurons in Thyroid and

Estrogen Treated Animals

Figure 20. Number of Contacts on Cell Body of Neurons in Thyroid And Estrogen Treated Animals

Figure 21. Number of Contacts on Dendrites of Neurons in Thyroid And Estrogen Treated Animals

Figure 22. Density of Contacts on Cell Body of Neurons in Thyroid 
And Estrogen Treated Animals

Figure 23. Density of Contacts on Dendrites of Neurons in Thyroid And Estrogen Treated Animals

Figure 24. Non-Breeding Season Animal Neuron

Figure 25. Non-Breeding Season Animal Neuron with Synapsin 51

Figure 26. Breeding Season Animal Neuron $\quad 52$

Figure 27. Breeding Season Animal Neuron with Synapsin 52

Figure 28. A15 Dopaminergic Nucleus and Synapsin at 20X Mag. $\quad 53$

Figure 29. Neurolucida Tracing of Anestrous Neuron 53

Figure 30. Neurolucida 3-D Reconstruction of Anestrous Animal Neuron

(Tilted at $45^{\circ}$ angle) $\quad 54$

Figure 31. Neurolucida 3-D Reconstruction of Anestrous Animal Neuron

A Side View (Tilted at $90^{\circ}$ angle)

Figure 32. Neurolucida 3-D Reconstruction of Anestrous Animal Neuron

A Top View (Tilted at $180^{\circ}$ angle)

55

Figure 33. Neurolucida 3-D Reconstruction of Anestrous Animal Neuron

A Side View (Tilted at $270^{\circ}$ angle) 


\section{CHAPTER ONE: INTRODUCTION}

The female reproductive axis consists of many organs and hormones. The steroid hormones, estrogens, androgens, and progesterone, are synthesized in the gonads and adrenal cortex from cholesterol. The estrogens (estradiol-17 $\beta$ being the most potent estrogen) are produced from androgen precursors, which were converted from progesterone, and progesterone is converted from cholesterol. Gonadotropin-releasing hormone $(\mathrm{GnRH})$ is released from neurons in the hypothalamus. GnRH acts on the anterior pituitary gland to regulate release of two other hormones, follicle-stimulating hormone (FSH) and luteinizing hormone (LH). FSH stimulates the development of ovarian follicles, and LH induces ovulation of the ovum along with inducing formation of the corpus luteum. FSH and LH are synthesized and released from the anterior pituitary in response to $\mathrm{GnRH}$, and both of these hormones act in the production and secretion of the steroid hormones. The steroid hormones in turn exert negative feedback on the GnRH-secreting neurons of the hypothalamus and on the anterior pituitary endocrine cells that produce FSH and LH. These negative feedback loops are an important part of the reproductive axis and are essential to female reproduction.

$\mathrm{GnRH}$ is released into hypothalamic-hypophyseal portal vessels from nerve terminals in the hypothalamus in bursts or pulses (Levine et al. 1982 and Clarke and Cummins 1982). The mechanism producing the pulsing pattern of release of GnRH is unclear at this time. There is some evidence that it may be an intrinsic property of GnRH neurons (Kokoris et al. 1988; Krsmanovic et al. 1992; Terasawa et al. 1999), or there may be a more complex interaction between many neurons. The pulses of GnRH are stimulate the pulses of LH secretion from the anterior pituitary (Manter et al. 1991). 
Changes in GnRH and LH pattern occur through the year determining the time of ovulation.

The steroid hormones from the ovaries modulate the output of $\mathrm{GnRH}$ and $\mathrm{LH}$, and thus control the timing of the estrous cycle. Ewes ovariectomized during the luteal phase show an increase in frequency and amplitude of LH pulses (Goodman and Karsch 1980). Replacement of progesterone causes a decreased frequency but does not decrease amplitude. Conversely, replacement with estradiol causes a reduction in amplitude but no decrease in frequency. Therefore, the frequency of LH during the estrous cycle is modulated through progesterone while the amplitude is modulated through estradiol. However, during the follicular phase of the estrous cycle there is an increase in frequency of LH pulses, and this increase in LH pulses is not caused solely by the removal of progesterone. It was found that estradiol causes a further increase in LH frequency after the removal of progesterone (Karsch et al. 1983).

This all leads to a hypothesis of the way in which the feedback effects of the steroid hormones work to modulate the pulses of LH during the estrous cycle (Karsch et al 1984). During the luteal phase of the cycle, elevated progesterone reduces the frequency of the release of $\mathrm{GnRH}$, and of $\mathrm{LH}$ pulses, while the elevated level of estradiol keeps the amplitude of the LH pulses down (Karsch et al. 1984). This serves to prevent ovulation by keeping the level of LH below that needed to support follicular maturation and cause the preovulatory estradiol rise. During the follicular phase of the estrous cycle, progesterone is withdrawn and the LH pulses are allowed to increase in frequency (this is further increased by the actions of estradiol). However, estradiol continues to keep the amplitude of the LH pulses low (Karsch et al. 1984). Serum LH concentration now rises 
because of the sustained increase in LH pulse frequency. The rise in LH causes follicular maturation and a preovulatory increase in estradiol, which induces the LH surge leading to ovulation (Karsch et al. 1984).

The negative feedback effect of steroid hormones is also observed during the anestrous season. During anestrus, estradiol acts to suppress LH pulse frequency, unlike in the breeding season when estradiol only suppressed LH pulse amplitude. During the spring and summer, when estradiol is given to ovariectomized ewes, the level of LH in the serum is undetectable (Legan and Karsch 1979). This demonstrates a marked increase in sensitivity of the estrogen negative feedback mechanism during the anestrus season. This increased sensitivity decreases the GnRH and LH release and prevents the rise in LH pulse frequency required for the preovulatory estradiol rise and thus inhibits ovulation. 


\section{CHAPTER TWO: REVIEW OF LITERATURE}

\section{General Overview of Seasonality in the Ewe}

Many mammals have evolved seasonal breeding in order to maintain the survival of the species. Because factors such as weather and food availability are important to determining the survival of the young it is important that they are born at a time of the year when these factors benefit them (Lincoln and Short 1980). These are called ultimate factors and are the selective forces used by natural selection to develop the seasonal pattern of reproduction (Bronson 1989; Goodman 1999). The offspring should be born, for example, when there is good weather and plentiful food, such as, the spring or summer. Seasonal conditions are also important to ensure that the mother is able to maintain an energy reserve in order to feed and care for the young (Goodman 1999).

The timing of the birth season is not normally determined by ultimate factors but by what are called proximal factors. The breeding season must also be timed correctly, since after conception there is a fixed gestation period (Lincoln and Short 1980). For this reason the animal relies on proximal cues in determining the breeding season. These proximal cues predict the time of year, and are most often environmental attributes, such as, photoperiod and nutrition, but they can be other signals, such as, hormonal and chemosensory cues (Lincoln and Short 1980; Bronson 1989; Goodman 1999).

The breeding season of the sheep is typical of many species. They breed during the fall and winter months and go into a period of anestrus during the spring and summer months. This is known as being a short day breeder, while species, such as, ferrets, voles, and horses are known as long day breeders because they breed during the long days of summer (Bittman, Karsch, and Hopkins 1983). 


\section{Photoperiod and Melatonin}

The major proximal cue driving the seasonal change in breeding of the sheep is photoperiod (Goodman 1999). Since length of day during a particular season is relatively constant from year to year, the duration of light can be a good indicator of the season.

The photoperiodic signal controls the secretion of an important hormone, melatonin made in the pineal gland. Anatomically, the pineal is indirectly linked to the retina. Light-dark signals are transmitted, via a series of neural pathways that include the suprachiasmatic nuclei and superior cervical ganglia, to the pineal (Karsch et al. 1984; Malpaux et al. 1996 ). At the pineal those signals are transduced to the hormonal signal, melatonin. Melatonin is only secreted in the dark so that changes in duration of melatonin secretion provide information about day length.

Melatonin has been shown to be the hormone used by the animal to respond to day length. In pinealectomized sheep, prior to the infusion of melatonin there is no reproductive response to photoperiod, and after systemic administration of melatonin, the reproductive response to photoperiod is restored. This demonstrates that sheep use melatonin as the photoperiodic signal to drive reproduction, and that melatonin probably works from the pineal through the vasculature (Bittman, Dempsey, and Karsch 1983). There is also good evidence for melatonin, released from the pineal, controlling changes in estradiol inhibition of LH (Bittman, Karsch, and Hopkins 1983). Exactly how melatonin mediates the effects of photoperiod on reproductive state is an important issue, and, through several studies, the complexity of this issue has been realized.

In an early study, melatonin was infused into sheep for a fixed duration to mimic the duration of melatonin naturally secreted by the pineal during the long-days. 
These infusions were given either at night or in the middle of the day. The reproductive responses to the infusions were the same; it was therefore hypothesized that duration is important and not the phase or time when melatonin is secreted (Wayne, Malpaux, and Karsch 1988). However, it was also demonstrated that the response to duration was dependent on the previous melatonin pattern (Robinson and Karsch, 1987). It is therefore possible to get an opposite response from the same duration of melatonin. It was then hypothesized that photoperiodic information is conveyed through changes in nocturnal melatonin patterns (Wayne, Malpaux, and Karsch 1988).

It has been demonstrated in the ewe that the pineal is an important regulator of seasonal changes. It is not, however, essential for the transition from the breeding season to anestrus. Instead the pineal is mainly involved in synchronizing the ovarian cycles; when the pineal is removed the animal still demonstrates changes in breeding condition but these are out of synchrony with other pinealectomized animals and with the season (Bittman et al., 1983). A great deal of evidence has accumulated demonstrating that there is an endogenous reproductive rhythm, and that melatonin acts to regulate this rhythm. One of the most convincing of these studies was a five-year study (Karsch, Robinson, Woodfill, and Brown, 1989) in which ovariectomized ewes given estrogen replacement were maintained either outdoors in natural conditions or indoors in a fixed, short photoperiod. Serum concentrations of luteinizing hormone and prolactin (PRL) were measured. The results revealed that ewes maintained outdoors have normal cycles of LH and PRL with a period of 365 days, and animals housed indoors had cycles of LH and PRL with periods that differed from 365 days. Also the animals maintained indoors were out of synchrony with each other and with animals maintained outdoors (Karsch, 
Robinson, Woodfill, and Brown, 1989). This demonstrates clearly there is an endogenous rhythm for regulation of reproduction. In subsequent experiments it was demonstrated that melatonin patterns synchronizing the endogenous rhythms are season specific (Wayne, Malpaux, Karsch 1990 and Woodfill, Robinson, Malpaux, Karsch 1991). Pinealectomy at different times of the year had different effects on both onset and duration of the subsequent breeding season. At some times of the year, such as the summer solstice, pinealectomy had an effect within a short time (one to two months) while at other times of the year, such as the autumnal equinox, pinealectomy didn't appear to have an effect until one year later (Wayne, Malpaux, Karsch 1990). The pattern of melatonin administration is also important in determining the specific season. For example, patterns of melatonin infused into pinealectomized sheep that mimic the pattern of melatonin seen in pineal intact sheep during the spring equinox and the summer solstice are the most effective patterns for synchronizing the endogenous reproductive rhythm (Woodfill, Wayne, Moenter, and Karsch 1994). It was thus hypothesized that synchronization in the spring and summer prepares the animal to mate in the autumn (Woodfill, Wayne, Moenter, and Karsch 1994).

The site of action of melatonin is open to some controversy. There are two proposed sites of action, one is the pars tuberalis and the second is the medial basal hypothalamus. In an autoradiographic study, melatonin binding sites were found in the pars tuberalis portion of the pituitary stalk, but not in the nearby median eminence (Reviers, Ravault, Tillet and Pelletier 1989). There was also an absence of labeling in the pineal gland showing that melatonin is probably not working back on the pineal itself. 
Some low density binding was found in the mediabasal hypothalamus (MBH) using specific high-affinity binding of 2-[ $\left.{ }^{125} I\right]$ iodomelatonin (Bittman and Weaver 1990).

The proximity of the pars tuberalis (PT) to the pituitary and hypothalamus make it of particular interest in the role of melatonin. Several experiments have implicated the pars tuberalis in regulation of prolactin, but not LH secretion (Malpaux, Daveau, Maurice, Locatelli, Thiery 1994; Malpaux, Skinner, Maurice 1995). Melatonin implants cause a short day effect, and, thus, result in an increase in LH secretion. Melatonin microimplants placed into the pars tuberalis had little effect on the stimulation of LH secretion but had significant effect on prolactin release (Malpaux, Skinner, Maurice 1995). Conversely, placement of implants in the MBH affected stimulation of LH secretion but not prolactin secretion (Malpaux, Skinner, Maurice 1995). There is still the possibility that melatonin has either diffused from the MBH to the PT, in the $\mathrm{MBH}$ placement experiment, or it has diffused from the PT to the $\mathrm{MBH}$, in the PT placement experiment. The limited spread of radiolabeled-melatonin placed into these areas provides evidence against this possibility (Lincoln, Maeda 1992; Malpaux et al. 1993; Malpaux, Skinner, Maurice 1995). The mechanism that melatonin uses in the MBH to regulate LH secretion is largely unknown; the long delay (40-50 days) between melatonin treatment and LH response is indicative of a complex regulation (Malpaux et al. 1996).

\section{Estradiol Negative Feedback}

During the anestrous season, the ability of estradiol to suppress GnRH secretion increases. Estradiol plays two roles, one is the positive feedback induction of the LH surge during the breeding season and the other is the negative feedback suppression of LH pulse frequency in the anestrous season and LH pulse amplitude during the breeding 
season. During the breeding season, most suppression of LH is exerted by progesterone via endogenous opioid peptides (Ferin, Van Vugt, and Wardlaw 1984; Whisnant, Havern, and Goodman 1991).

It is well established that during the non-breeding season there is an estradiol negative feedback mechanism that decreases LH secretion. In ovariectomized sheep without estradiol replacement, no decrease in LH pulse amplitude is seen (Legan, Karsch, and Foster 1977; Karsch, Goodman, and Legan 1980; Goodman and Karsch 1980). In ovariectomized sheep given estradiol replacement, LH pulse frequency is decreased during the non-breeding season while the LH pulse amplitude is subdued during the breeding season.

Where estradiol acts is unclear at this point. Short-term negative feedback effects have been shown to occur in the pituitary, but negative feedback that occurs during the anestrous season is thought to occur in the hypothalamus (Legan, Karsch and Foster 1977; Karsch, Goodman, and Legan 1980; Clarke, 1987). One explanation for $\mathrm{E}_{2}$ inhibition of GnRH pulse frequency would be that estradiol acts via another neural pathway that then contacts GnRH neurons to inhibit their activity. This is somewhat complicated because GnRH neurons appear to be scattered throughout the forebrain, from the olfactory bulb to the posterior hypothalamus (Lehman et al. 1997), raising the possibility of regional specificity. For example, the medial basal hypothalamus has been isolated as an important region in GnRH regulation. Using fos, an immediate early gene product, as an indicator of neuronal activity in GnRH neurons, it has been suggested that GnRH neurons in the MBH may be involved during pulsatile secretion of LH (Boukhliq, Goodman, Berriman, Adrian, and Lehman 1999). When animals were given an 
antagonist to endogenous opioid peptides during the luteal phase in order to increase $\mathrm{LH}$ pulse frequency, fos expression was increased only in $\mathrm{GnRH}$ neurons in the $\mathrm{MBH}$. Similarly, when LH pulse frequency was induced in estrous ewes by exposure to rams, fos expression was again seen only in GnRH neurons in the MBH (Boukhliq, Goodman, Berriman, Adrian, and Lehman 1999). This offers some evidence that GnRH neurons in the MBH may be responsible for episodic secretion of LH and, therefore, the system for the transition into anestrus may also be in this area. Since GnRH neurons in this area (and other areas) do not contain estrogen receptors this leads to the examination of other afferent neural groups as being an important mediator of estradiol negative feedback (Herbison, Robinson, and Skinner 1993; Lehman and Karsch 1993). One neural group that has received a lot of attention is the A15 dopaminergic neurons.

\section{Neural Systems Mediating Change in Response to Estradiol Negative Feedback}

The decrease in LH pulse frequency that occurs in anestrus via estradiol negative feedback occurs through a decrease in GnRH neuron output (Karsch et al. 1984). This suppression of GnRH neural activity occurs through a neural mechanism in the hypothalamus (Pau and Jackson 1985). A treatment with pentobarbital anesthesia can inhibit the decrease in LH pulses that occur during anestrus, and this effect is not observed during the breeding season (Goodman and Meyer, 1984). It then can be hypothesized that a set of neurons is acting during the non-breeding season that is not acting during the breeding season, and mediate the negative feedback effect of estrogen during the non-breeding season.

It is, thus, important to identify the potential neurotransmitters involved. In 1985 Goodman and Meyer performed an experiment where antagonists to several potential 
neurotransmitters were administered. Two of these antagonists were pimozide, a dopaminergic antagonist, and phenoxybenzamine, a $\alpha$-adrenergic antagonist. It was found that both of these increased pulsatile LH secretion during the non-breeding season, but neither increased pulsatile LH secretion during the breeding season. This provided evidence for dopaminergic or adrenergic neurons as possible pathways for inhibition of GnRH. Subsequent work provided conflicting data in the adrenergic system (Goodman et al. 1995), but consistent support for the DA system (Havern, Whisnant, and Goodman 1994; Lehman et al. 1996; Goodman et al. 2000).

It is then important to identify the area of the hypothalamus where these inhibitory neurons may be located. Frontal deafferentation in the hypothalamus near the optic chiasm can eliminate the seasonal effects on the suppression of LH pulses (Pau and Jackson 1985), and blocks the regular negative feedback actions of $E_{2}$ in anestrus (Whisnant and Goodman 1994). The retrochiasmatic area of the hypothalamus then becomes the region of main interest. A study was performed where a neurotoxin was injected into the retrochiasmatic area of anestrus ewes (Thiery et al. 1989). This neurotoxin was 6-hydroxydopamine, a neurotoxin against catecholaminergic neurons. When the neurotoxin was administered, estradiol did not decrease LH pulses to the level that was seen in control animals (Thiery et al. 1989). This data supports the retrochiasmatic area as a site of interest and catecholaminergic neurons as possible components in the inhibitory machinery.

The catecholaminergic group A15 is located in this region of the brain, and these A15 neurons contain dopamine-immunoreactive cell bodies (Tillet et al. 1990). This was found by using antibodies against tyrosine hydroxylase, the rate-limiting enzyme in the 
synthesis of dopamine, and antibodies against aromatic amino acid decarboxylase, and antibodies against dopamine. The A15 neural group of the hypothalamus then becomes an obvious potential site of estradiol negative feedback. The A15 nucleus is a small nucleus that lies medial to the optic tracts and is heavily stained with antibodies against tyrosine hydroxylase (Tillet and Thibault 1989).

Havern et al. (1994) tested the role of the A15 and A14 (DA neurons located rostral to the A15) in seasonal changes in $E_{2}$ negative feedback by destroying these cell groups with radiofrequency lesions. After lesioning, the animals were given estradiol implants and the effect of a dopamine antagonist was examined. It was found that estradiol inhibition of LH was partially decreased in ewes with lesions in either the A15 or A14, and when an antagonist was given it did not stimulate LH pulse frequency. This provides evidence specifically for the role of the A15 or the A14 cell dopaminergic neural groups. There was no effect of similar lesions on estrogen negative feedback in the breeding season. Interestingly, it was also found that there are catecholaminergic fibers apparently between the A15 and A14 cell groups (Havern, Whisnant, and Goodman 1994).

Evidence that $\mathrm{E}_{2}$ acts on these dopamine neurons was provided in an experiment where tyrosine hydroxylase activity was measured when estradiol was given to ewes during long days (Gayrard et al. 1994). The levels of TH metabolites, produced from the activity of TH enzymes, were measured in two specific areas, the lateral retrochiasmatic area and the caudate nucleus. It was found that $\mathrm{E}_{2}$ increased $\mathrm{TH}$ activity in the lateral retrochiasmatic area, while no effect was seen in the caudate nucleus. They also 
confirmed that metabolites from dopamine synthesis come from A15 dopamine neurons and not adrenergic afferents onto the dopamine neurons.

Further evidence for actions of $\mathrm{E}_{2}$ in $\mathrm{A} 15$ and A14 groups came from a study using the immediate early gene product Fos (as well as Fos-related antigen) as a marker of cell activity (Lehman, Durham, Jansen, Adrian, and Goodman 1996). There were four groups of ovariectomized ewes in this study: two in anestrus, one with estradiol implants and one without estradiol implants, and two during the breeding season, one with estradiol implants and one without estradiol implants. It was found that the group with estradiol implants during anestrous had an increase in Fos and Fos related antigen expression in the A15 greater than the other groups lending support for the hypothesis that $\mathrm{E}_{2}$ activates the $\mathrm{A} 15$ group during the non-breeding season.

A different approach to assessing estradiol actions was performed by Beccavin, Malpauxs, and Tillet (1998) using the same experimental groups given in the previously discussed experiment by Lehman et al done in 1996. In this experiment the level of TH mRNA in neurons from the A15 was measured using a cDNA probe and in situ hybridization. Surprisingly, they found that the levels of TH mRNA increased in the breeding season estrogen treated group greater than all the other groups. This indicates that the increase in activity of the enzyme observed previously (Gayrard et al. 1994) is probably not caused by an increase in transcription of the gene. It is then most likely due to either an increase in translation or changes in phosphorylation of the enzyme itself.

More evidence for the role of the A15 neural group was found in a study using recordings of multiunit electrical activity (Goodman, Thiery, Delaleu, and Malpaux 2000). In this study electrodes were chronically placed unilaterally in the A15 area of the 
hypothalamus of ovariectomized ewes during the long days of summer. Monitoring of electrical activity began 4 hours before the insertion of a subcutaneous $E_{2}$ implant, and continued for another 24 hours after the start of $\mathrm{E}_{2}$ treatments. Control ewes received blank implants. The results indicated a gradual 24-hour long increase in electrical activity of the $\mathrm{A} 15$ in the ewes receiving the $\mathrm{E}_{2}$ implants, while the ewes receiving the blank implants showed no increase in electrical activity. This provides more evidence that the neurons in the A15 area of the hypothalamus are stimulated by $\mathrm{E}_{2}$ during the anestrous season. There is, thus, strong support for the hypothesis that the A15 nucleus is a key component for the system mediating $\mathrm{E}_{2}$ inhibition of $\mathrm{LH}$ during the non-breeding season.

These A15 neurons probably project to the median eminence (ME) since the dopaminergic terminals in the ME are implicated in the melatonin regulation of $\mathrm{LH}$ (Maplaux et al. 1996). Short day exposure leads to decrease in TH content in the ME indicating a decrease in dopaminergic activity in the ME (Thiery et al. 1995). Several studies link melatonin to this TH activity and subsequently to LH output. Stimulation of LH secretion using melatonin implants (melatonin implants cause a short day effect, and, thus, result in an increase in LH secretion) causes a parallel decrease in TH activity, and blockade of TH in this area results in an increase in LH (Viguie 1995; Malpaux et al. 1996). This modulation of TH by melatonin occurs both in ovariectomized ewes and ovariectomized ewes treated with estradiol indicating this is an estrogen independent mechanism (Viguie 1995; Malpaux et al. 1996).

When the antagonists phenyoxybenzamine and pimozide are administered to specific areas of the hypothalamus (the preoptic area $[\mathrm{POA}]$, retrochiasmatic area $[\mathrm{RCh}]$, 
and the median eminence $[\mathrm{ME}]$ ), differences in LH patterns can be seen (Havern, Whisnant, and Goodman 1991). The dopamine antagonist, when placed in either the $\mathrm{RCh}$ or the ME, increases LH pulse frequency, but the norepinepherine antagonist does not have this effect. However, the norepinepherine antagonist, when placed in the POA, does stimulate GnRH pulse frequency (Havern, Whisnant, and Goodman 1991). This is consistent with the hypothesis that dopaminergic neurons in the retrochiasmatic area may mediate the effects of estradiol on inhibition of GnRH secretion, and this supports the A15 dopaminergic neurons as possible mediators.

A15 neurons themselves do not have estrogen receptors. Therefore, it becomes important to look at the afferent input onto these neurons (Lehman and Karsch 1993). A study by Tillet and Thibault in 1994 examined this issue, primarily looking at adrenergic input on the A15. Using antibodies against tyrosine hydroxylase and dopamine- $\beta$ hydroxylase, an enzyme found in noradrenergic neurons, the relationship between these two sets of neurons was examined. Using light microscopy, noradrenaline fibres were found close to the dopaminergic neurons and using electron microscopy both catecholaminergic and non-catecholaminergic inputs were found on A15 cells. Since, when using electron microscopy, they only looked at tyrosine hydroxylase they did not show whether the inputs directly on A15 neurons were dopaminergic or adrenergic specifically.

Tract tracing studies were done to identify potential afferent innervation of the A15, and also to identify potential efferent innervation (Jansen et al. 1997). A mixture of cholera toxin- $\beta$ subunit and biotinylated dextran amine were injected into anestrous ewes. Tract tracing revealed afferent input to the A15 from the following areas: lateral septum, 
diagonal band, bed nucleus of stria terminalis, medial preoptic area, anterior hypothalamic area, suprachiasmatic nucleus, paraventricular nucleus of thalamus and the paraventricular, supraoptic, arcuate and dorsomedial hypothalamic nuclei. Further tract tracing studies were done in which ER positive cells were also identified (Jansen et al. 1999). Neurons that both project to the A15 and are ER positive neurons were found in the medial preoptic area, anterior hypothalamic area, ventromedial hypothalamic nucleus, and arcuate nucleus. These data all lend support to the POA being one area of interest for the regulation of the dopaminergic A15 nucleus.

The ventromedial preoptic area was also isolated as a potential region for the action of estradiol during the non-breeding season (Stefanovic, Adrian, Jansen, Lehman, and Goodman 2000). This experiment also used Fos and Fos- related antigens as indicators of neural activity. Low doses of estradiol were given to ewes to suppress LH, and Fos/ER $\alpha$ colocalization was examined through the entire hypothalamus. It was found that when Fos activity increased in the A15 region there was also an increase in Fos/ER $\alpha$ colocalization in the ventromedial preoptic area. Another experiment that examined whether seasonality changed this response, confirmed the $\mathrm{E}_{2}$-induced increase in Fos/ER $\alpha$ colocalization in anestrus, but there was no increase in Fos/ER $\alpha$ colocalization during the breeding season. These data provide indirect support that the medial pre-optic area may contain the neurons that are the link, or part of the link, between estradiol and the increased activity of the A15 dopaminergic neurons that result in the inhibition of the release of $\mathrm{GnRH}$.

Further evidence for the role of the vmPOA came from a study in which estradiol implants were directly inserted in the ventromedial preoptic area (Anderson et al. 2001). 
In this study ovariectomized ewes received either empty or estradiol-containing implants in the vmPOA or they received subcutaneous estrogen implants. During anestrus LH pulse frequency was suppressed in ewes with either the subcutaneous implant or the implant containing estradiol directed at the vmPOA. Sulpiride, a dopamine receptor antagonist, increased LH pulse frequency seen in the group with the estradiol implants directed to the vmPOA, but not in ewes with blank implants During the breeding season this suppression of LH was not seen in either the groups with subcutaneous implants or the implants directed at the vmPOA. The conclusion that can be drawn from this is that the vmPOA provides either the initial step in estrogen suppression of GnRH in anestrus or that it is at least a crucial step.

In summary, A15 neurons apparently mediate the suppression of GnRH by estradiol during the anestrous season, but these neurons do not contain estrogen receptors. Neurons in the vmPOA may mediate the interaction of estrogen with the dopaminergic neurons of the A15. The A15 neurons then contact GnRH neurons in the ME where GnRH secretion is inhibited.

\section{Thyroid Hormone in Reproduction}

Thyroid hormones have long been recognized as playing an essential part in seasonal reproduction in birds. It was first discovered that thyroid hormones are important in seasonal reproduction in Starlings in the 1940s by Woitkewitsch and this 
was later expanded on in the 70's and 80's by other researchers. More recently, evidence has developed that thyroid hormones are also essential to the sheep in seasonal reproduction.

Early work was done in ewes to determine the effect of thyroidectomy in reproduction (Nichols et al. 1988). It was found that thyroidectomized ewes continuously cycled for very long periods of time or they enter anestrus at varied times. In a later experiment (Follett and Potts 1990), animals were not thyroidectomized but were given methylthiouracil, a drug treatment that renders the animals hypothyroid. In hypothyroid animals the duration of the reproductive period is significantly longer than in euthyroid animals.

Parkinson and Follett (1994) also examined the role of thyroid hormone in seasonal reproduction in rams. In this experiment, rams were thyroidectomized in March and were maintained in natural photoperiods with intact rams. In the thyroidectomized rams scrotal circumference increased more rapidly between April and August than in the thyroid-intact rams. In another experiment, rams were thyroidectomized in September and maintained with intact rams in either short days or long days. It was found that thyroidectomized rams had plasma FSH concentrations and scrotal circumference values similar to those that would be seen during the breeding season through the entire experiment, and intact rams had a pattern of FSH secretion typical of normal seasonal changes where values reached a nadir in December and January. These experiments gave some of the first indications that thyroid hormone might play a key role in seasonal reproduction. It was also observed that, when rams are thyroidectomized, the normal suppression of reproduction during the non-breeding season is overcome. 
Further evidence for the role of thyroid hormone was obtained in the ewe. The effect of thyroidectomy on prolactin, melatonin, and LH secretion in OVX+E ewes was examined (Dahl et al. 1994). It was found that thyroidectomy has no effect on prolactin or melatonin secretion. However, when measuring LH it was found that, during the transition to long days, thyroidectomized ewes did not have the usual drop in LH seen in normal intact ewes. This proved that thyroid hormone is probably a component involved somewhere between the pineal and the GnRH neurosecretory system, and is not involved in prolactin secretion indicating that thyroid hormone is not involved in all photoperiodic signal processes.

It was found that the reason $\mathrm{LH}$ is not suppressed during the long days in thyroidectomized ewes is not because of increased steroid metabolism, or related to an alteration in the secretion of thyrotropin-releasing hormone (Moenter et al. 1991; Dahl et al. 1994). It was also found that thyroid hormone does not effect LH secretion during the breeding season (Nicholls et al. 1988). All of this points to a direct action of thyroid hormone on the nervous system. When $\mathrm{T}_{4}$ is infused directly into the cerebrospinal fluid of thyroidectomized ewes, a normal drop in $\mathrm{LH}$ is seen during the transition from breeding season to non-breeding season (Viguie et al. 1999). However, when the same amount of $T_{4}$ is given peripherally to thyroidectomized ewes the drop in LH is not seen. This provides evidence that $\mathrm{T}_{4}$ most likely acts in the brain to promote the seasonal transition of reproductive states.

The mechanism of thyroid hormone action in the transition from the breeding season to anestrous season is not completely clear at this time. However, there are two important points that should be stressed: 1) thyroid hormone plays a permissive role in 
seasonal reproduction, and 2) thyroid hormone appears to act in a specific window of time (Karsch et al. 1995). Thyroidectomized ewes appear to maintain a breeding season level of LH all year round; the question would be then, is there a specific amount of thyroxine that promotes the transition into anestrous. This question was answered by an experiment where the levels of thyroxine were varied in increments to determine if animals with low levels of thyroxine would not have a decline in LH during anestrous (Dahl et al. 1995). The results show that LH does decline in winter in all animals receiving thyroxine, and animals that are thyroidectmized do not have a decline in $\mathrm{LH}$ in the winter, demonstrating that thyroid probably does work permissively in allowing the breeding season to anestrous transition.

The issue of the time when thyroid hormone acts in the seasonal transition was addressed in an experiment with thyroidectomized ewes given thyroxine replacement at different times in the year (Thrun et al. 1993). In this experiment ewes were thyroidectomized early in the breeding season and given thyroxine either at the time of thyroidectomy, one month later, or two months later. There were, thus, short periods of time when no thyroxine was present. It was found that all experimental groups went into anestrous at the same time regardless of when the thyroxine treatment was given demonstrating that it is important for thyroxine to be present only at the end of the breeding season. In other experiments it was found that thyroid hormone is required sometime in the last 3-4 months of the breeding season (Wayne et al. 1990, and Thrun et al. 1993). This all leads to the conclusion that there must be a specific window of time when thyroid hormone is necessary for the transition from breeding season to non- 
breeding season, and that window is probably during the last 3-4 months of the breeding season.

Thyroid hormone exhibits an annual cycle of serum $\mathrm{T}_{4}$ concentration. Circulating $\mathrm{T}_{4}$ was measured in thyroid-intact ewes over a 2-year period of time (Webster et al. 1991). The results indicate an increase in serum $T_{4}$ concentration late in the breeding season (a peak value in the winter), and a decrease in late anestrus (a nadir in summer). However, this change has no apparent importance because low amounts of $\mathrm{T}_{4}$ are sufficient to permit the transition from the breeding season to the non-breeding season.

The exact site where thyroid hormone acts is unknown at this time, and the mechanisms of thyroid hormone action in seasonal reproduction is unclear. It is speculated that thyroid hormone acts in the central nervous system, specifically on GnRH neurons, but there is not much evidence for this at this time (Karsh et al. 1995). One possibility could be that thyroid hormone acts to regulate neural plasticity. This regulation could occur either in GnRH neurons or, as examined in this work, in the A15 dopaminergic neurons.

There is an accumulating body of evidence that thyroid hormone is a regulator of neural plasticity in many neural systems. One experiment where thyroid hormone's role in neural plasticity has been examined was done on the A10 dopaminergic neurons of the olfactory tubercle in the rat. It was found in adult rats that when some of these neurons are lesioned, the remaining A10 neurons sprout collaterals, and it is speculated that this is a result of removal of a non-dopaminergic input (Gilad and Reis 1979). This effect was examined in perinatal rats that were hypothyroid, and this sprouting is suppressed in animals that are hypothyroid prenatally or in the early postnatal period (Gottesfeld 
Garcia, and Chronister 1987). However, animals that are hypothyroid after maturity do not experience suppression in lesion-induced collateral sprouting. There is also significant evidence that thyroid hormone can regulate expression of growth factors and other peptides that are potentially involved in regulating neural plasticity in the adult brain (Calza, Aloe, and Giardino 1997).

\section{Neural Plasticity in Reproduction}

Neural plasticity contributes an important part in reproductive changes in many species. Neural plasticity can be a change in number of synapses or a change in neural morphology itself. Much of the work in neural plasticity in adults has been done in one species in particular, the songbird.

Singing in the songbird is predominantly a male activity. It is a learned behavior that males do as part of a courtship behavior for females (Marler and Waser 1977). This behavior that is unique to males gives researchers an opportunity to examine the sexually dimorphic nature of neurons in the robustus archistraitalis (RA), a nucleus in songbirds that is involved in controlling singing activity (DeVoogd and Nottebohm 1981). Dendrites in the neurons of this nucleus tend to be longer and branch more in the male than in the female (DeVoogd and Nottebohm 1981).

When female songbirds are given a testosterone treatment they can be induced to sing similar to the males and likewise a similar neuronal change is seen (DeVoogd and Nottebohm 1981). When female songbirds are ovariectomized and given physiological doses of testosterone the dendritic trees of the neurons of the RA resemble those of the male. Non-treated ovariectomized females have dendrites that are significantly shorter than those of intact females, and when ovariectomized females are given estradiol and 
dihydrotestosterone they resemble intact females. This provides evidence that not only are the neurons of the RA in songbirds sexually dimorphic but also that gonadal hormones can affect the morphology of these neurons; specifically gonadal hormones induce dendritic growth.

Not only can gonadal hormones affect neuronal morphology in the songbird, but they can also induce other plastic changes. One such change is an actual increase in the size of the robustus archistriatalis seen in males compared to females, and this is also in testosterone treated females (DeVoogd, Nixdorf, and Nottebohm 1985). There are also increases in the number of synapses formed on the neurons in the RA, and an increase in number of synaptic vesicles in these synapses. These changes in synapses are not only induced by hormonal treatment but can also be caused by a change in season. Spring-like conditions cause an increase in synapse formation and an increase in number of synaptic vesicles compared to fall-like conditions. These seasonal changes are thought to occur through photoperiod. Structural changes in the dendritic tree of male songbirds have been seen when changes in photoperiod occur (Hill and DeVoogd 1991). Birds exposed to short day lighting have smaller denditic fields and fewer spines than birds exposed to long day lighting. Theses changes are similar to those that are caused by testosterone administration. Data shows that changes in behavior can be associated with changes in neural morphology. The fact that both hormones and seasonal condition can be involved show that the seasonal changes in the songbird are a result of a complex system where neuronal morphology is dictated by hormone level in addition to other conditions.

It is not well resolved whether the seasonal changes as a result of photoperiod are mediated through testosterone or whether they are a result of a steroid-independent 
mechanism (Smith, Benowitz, and Wingfield 1997). Testosterone alone or photoperiod alone can change the size of the RA. However, testosterone causes a greater increase in the size of the RA, and testosterone with photoperiod causes the greatest increase in RA size. It was thus hypothesized that photoperiod either supplements testosterone or it modulates the effects of testosterone (Smith, Benowitz, and Wingfield 1997).

Changes in neural plasticity of the songbird have been seen in another nucleus called the hypoglossal nucleus (Clower, Nixdorf, and DeVoogd 1989). This nucleus controls the syrinx in the songbird. It was shown that seasonal changes and manipulation of testosterone could change the number of synapses and the synaptic vesicle content of these synapses. These changes in synapse number and morphology are another example of the neural plasticity involved in the songbird induction of a singing behavior.

Synaptic plasticity during reproduction has also been observed in the rat arcuate nucleus. The arcuate nucleus is a hypothalamic center involved in the feedback regulation of gonadotrophins. During the rat estrous cycle the number of presynaptic terminals decreases in neurons in the arcuate nucleus in estrous (Olmos, Naftolin, Perez, Tranque, and Garcia-Segura 1989). There is also a decrease in number of synapses and an increase in the amount of glia in close apposition to neuronal membranes. This shows a decrease in contacts between proestrus and estrus with an increase in contacts between estrus and metestrus. These contacts are thought to be most likely inhibitory. It was also found that IGF-1 plays a role in synaptic remodeling and it is believed that both IGF-1 and astroglia are an essential part in synaptic remodeling in the rat estrous cycle.

In the adult female rhesus monkey, plasticity has been observed in GnRH neurons in the medial basal hypothalamus and the pre-optic area. Ovariectomized monkeys 
exhibit a decrease in innervation in both the $\mathrm{MBH}$ and the POA, and an increase in glial ensheathment in both areas (Witkin, Ferin, Popilskis, and Silverman 1991). After ovarian steroids are replaced there is an increase in innervation and a decrease in the amount of glial ensheathment. There also is an observable difference in innervation of neurons in the two areas with GnRH neurons in the $\mathrm{MBH}$ having more innervation than those in the POA.

There is also synaptic plasticity in the infundibular nucleus of the African green monkey. The infundibular nucleus (arcuate nucleus) in the monkey is also involved in reproduction. It contains GnRH neurons and electrical activity of this nucleus changes during the ovarian cycle. Estradiol replacement in ovariectomized monkeys causes a decrease in synaptic inputs and an increase in glial ensheathment of neurons in the infindibular nucleus (Naftolin, Leranth, Perez, and Garcia-Segura 1993). Thus, estradiol can cause synaptic plasticity and changes in glial orientation in the hypothalamus of both rats and monkeys.

There is also some evidence that neural plasticity may be involved in the onset of puberty in monkey, since there is an increase in synaptic density on GnRH neurons in the MBH in juveniles compared to adults (Plant and Perera 1997).

Finally, neural plasticity has been observed in the sheep pre-optic area. There is a change in input onto GnRH neurons in this area between the anestrous and breeding seasons (Xiong, Karsch, and Lehman 1997). An increase in number of synaptic inputs onto GnRH neurons during the breeding season has been observed providing evidence for seasonal plasticity in this system. There is also a difference in the number of contacts on GnRH neurons in the rostral preoptic area when comparing male and female sheep. 
Female lambs have twice the number of contacts that male lambs have, and androgenized female lambs have the same number of synapses as male lambs (Kim, Foster, and Wood 1999), demonstrating that steroids can play a role in controlling synaptic inputs during development.

A glycoprotein called PSA-NCAM, the polysialyated form of a neural adhesion molecule, can be used as a marker for neuroplasticity. In the sheep this molecule has been used to examine GnRH neurons in the preoptic area for changes in neural structure between the breeding season and non-breeding season (Viguie et al. 2001). During the breeding season there is an increased amount of PSA-NCAM labeling compared to the non-breeding season. This demonstrates that these GnRH neurons may be altered in some way in conjunction with the change in breeding season.

\section{Summary}

The sheep breeds during the short days of winter and goes into a seasonal anestrous during the long days of summer. This change is elicited through external cues such as photoperiod (the most widely studied cue). Melatonin is secreted from the pineal gland, and is a hormone that transduces photoperiod into a signal that determines the seasonal status of the animal. The means by which melatonin does this is not yet well understood.

The anestrous season is characterized by an increased sensitivity to estrogen negative feedback causing LH pulses that occur with less frequency than during the normal estrous cycle. The decreased LH prevents normal ovulation until the breeding season begins when a normal LH pattern begins. The change in LH pattern between the two breeding states is brought about by a change in estradiol negative feedback. During 
the non-breeding season estradiol causes a decrease in the frequency of LH. The mechanism behind the estradiol negative feedback during the non-breeding season is not completely understood.

The A15 dopaminergic cell group of the hypothalamus is considered to mediate the estrogen negative feedback during the anestrous season. The A15 nucleus is medial to the optic tracts in the medial basal hypothalamus. There is various pharmacological and anatomical evidence to support the A15 as a key component in the mechanisms behind the estrogen inhibition of luteinizing hormone in the non-breeding season. The indication is that the A15 group inhibits GnRH release from the median eminence. It would be intuitive to believe that estrogen works directly on the A15 neurons that then suppress the GnRH neurons. However, estrogen receptors have not been found on A15 neurons. Therefore it is important to look at input onto these neurons. The POA is a particular site of interest when looking at potential sites where estrogen is acting and where neural input from the POA may eventually reach the A15 nucleus.

Thyroid hormone has also been implicated in seasonal reproduction. It is necessary for thyroid hormone to be present in the breeding season for the animal to go into the non-breeding season. The action of thyroid hormone is most likely on the central nervous system. Three potential sites are GnRH neurons, the A15 neurons, or neurons that act on the A15 neurons. Thyroid hormone is implicated in neural plasticity as well.

Neural plasticity has been seen in many species including the sheep. It is not unusual for the number of contacts and synapses to change on a neuron. This is observed in GnRH neurons of the sheep during the change in breeding season. However, neural plasticity has not been studied extensively in the A15 nucleus. The role of thyroid 
hormone in the A15 or in mediating a plastic change in the A15 has also not been examined closely.

\section{Statement of Purpose}

The decrease in LH during anestrus is due to an increase in sensitivity to estradiol and this increased sensitivity to estradiol is mediated through the A15 dopaminergic nucleus of the hypothalamus. Since the A15 neurons do not contain estrogen receptors it is then important to look at the input onto these neurons. The hypothesis tested in the studies included in this thesis is that the neural input onto the A15 neurons changes with reproductive season mediating the change in inhibition of GnRH neurons. Additionally, thyroid hormones allow or modulate this alteration in input to A15 neurons. The objective of the research in this thesis was to examine differences in neural morphology and synaptic contacts on these A15 neurons. In experiment 1, I examined these neurons during the breeding season and non-breeding season. Specifically, I counted synaptic contacts on the A15 neurons, and determined if any other seasonal changes in neural structure occurred. In experiment 2, these parameters were also examined in thyroidectomized and $\mathrm{T}_{4}$ replaced ewes to determine if any changes in neural morphology might be dependent on thyroid hormone. 


\section{CHAPTER TWO: MATERIALS AND METHODS}

Animals:

Experiment 1: Fourteen adult blackfaced ewes of mixed breeds were used in this study. Animals were housed at the West Virginia University livestock farm sheep facility in an open barn where they were exposed to natural lighting and temperature. Surgeries and tissue collection were performed in an indoor facility. Ewes were moved indoors 2-3 days prior to any procedures, with lighting adjusted to simulate the natural photoperiod. Animals were fed a maintenance diet of silage, hay, and grain with free access to water. Animals were ovariectomized in either breeding season $(n=8)$ or anestrus $(n=6)$ via midventral laparotomy, using sterile procedures and pentobarbital anesthesia, and $0.5 \mathrm{~cm}$ long implants containing estradiol were inserted subcutaneously (sc) three weeks later. The animals were sacrificed one week later and tissue was collected. The West Virginia University Animal Care and Use Committee approved all procedures.

Experiment 2: The tissue used in this experiment was collected at the University of Michigan from an earlier study that examined the effects of $\mathrm{T}_{4}$ administered into the lateral ventricles (Viguie et al. 1999). Seventeen adult Suffolk ewes were maintained at the Sheep Research Facility in Ann Arbor, Michigan, and fed hey with free access to water and mineral licks. Animals for the thyroid intact group $(n=6)$ were ovariectomized via midventral laparotomy, using sterile procedures and pentobarbital anesthesia in August or September of 1995. They were immediately treated with constant release, 3cm sc estradiol implants. In December of 1996 animals from the thyroidectomized group $(\mathrm{n}=11)$ were ovariectomized and received constant release $3-\mathrm{cm}$ sc estradiol implants. Between November 14 and December 12, 1996 animals were thyroidectomized using 
sterile procedures and pentobarbital anesthesia followed by halothane adjusted during surgery, and some of the thyroidectomized animals $(n=5)$ received $T_{4}$ replacement $(9.6$ $\mu \mathrm{g} / \mathrm{day} ; 100 \mu \mathrm{g} / \mathrm{ml}$ solution) via canulation of the lateral ventricles infused by a pump. Estrogen treatment continued in all animals until April 10, 1997 when all estrogen implants were removed. On May 28, 1997 estrogen was replaced through constant release $1-\mathrm{cm}$ sc estradiol implants in half the animals of each group. This results in 6 thyroid intact animals, in which 3 receive estrogen treatment, 6 thyroidectomized animals, in which 3 receive estrogen treatment, and $5 \mathrm{~T}_{4}$ treated animals, in which 3 receive estrogen treatment (figure 1; table 1). Animals were sacrificed on June 4 and June 5, 1997 when brains were collected. All procedures were approved by the University of Michigan Committee on the Use and Care of Animals.

Tissue Preparation: Animals were heparinzed (two iv injections of 25,000 $\mathrm{U}$ heparin 10 min. apart), killed with an overdose of pentobarbital, and their heads were then immediately removed. The heads were perfused via both internal carotid arteries with 6L of $4 \%$ paraformaldehyde in $0.1 \mathrm{M}$ phosphate buffer containing, $10 \mathrm{IU}$ heparin/ml and $0.1 \% \mathrm{NaNO}_{3}$. Brains were removed from the head, and a tissue block containing the mediobasal hypothalamus and preoptic area was excised. The tissue block was postfixed for 24 hours at $4^{\circ} \mathrm{C}$, and then infiltrated with $30 \%$ sucrose in phosphate buffer. The tissue block was frozen and coronal sections of the hypothalami were cut at $50 \mu \mathrm{m}$ using a microtome and stored in cryopreservative at $-20^{\circ} \mathrm{C}$ until sections were stained. 
Double Immunofluorescence Staining Procedure (Coolen 7-2000): Three sections per animal were selected to stain using a dual fluorescence procedure for tyrosine hydroxylase (TH) and synapsin. The sections were selected based on gross anatomical landmarks to examine TH-positive neurons in the A15 dopaminergic nucleus. TH containing cells were labeled using mouse monoclonal antibodies against mouse tyrosine hydroxylase (Boehringer Manheim), and synapsin was identified with rabbit polyclonal antibody against bovine brain synapsin I (Molecular Probes).

All procedures were done on a shaker table. Sections were first washed in phosphate buffer for 3 hours, and then incubateded in phosphate buffer with $0.2 \%$ Triton$\mathrm{X}$ and $4 \%$ normal donkey serum for 1 hour at room temperature to decrease non-specific binding. Sections were then coincubated for 48 hours at $4^{\circ} \mathrm{C}$ on a shaker table with mouse TH antibodies (1:200) and rabbit synapsin antibodies (1:800) in phosphate buffer containing $0.2 \%$ Triton- $\mathrm{X}$ and $4 \%$ normal donkey serum. After three 15 minute washes in phosphate buffer, the tyrosine hydroxylase antibodies were conjugated to biotinylated donkey anti mouse (1:200) diluted in phosphate buffer with $0.2 \%$ Triton-X and $4 \%$ normal donkey serum during a 1 hour incubation at room temperature. Tissues were washed three times at 15 minutes, and rabbit synapsin antibodies were conjugated to donkey anti-rabbit-CY2 (a green fluorescent dye tagged to secondary antibody diluted to 1:100) during a 30-minute incubation at room temperature. After 3 more 15 minute washes in phosphate buffer, mouse $\mathrm{TH}$ antibodies conjugated to biotinylated donkey antimouse were labeled with CY3-conjugated streptavidin (a red fluorescent dye tagged to secondary antibody diluted to 1:200) during a 30-minute incubation at room temperature. The sections were washed 3 times at 15 minutes before mounting. 
Sections were mounted onto gelatin-coated microscope slides using a 50\% phosphate buffer and 50\% glycerol mixture. Coverslips were held in place using fingernail polish placed around the edges of the coverslips. Sections were not allowed to dehydrate before mounting on slides. Tissues from all treatment groups in each experiment were processed simultaneously over several days.

Tissue Analysis: Images of immunostained sections (Figures 24-28) were acquired using a Carl Zeiss Laser Scanning Microscope (confocal microscope). In experiment 1, images were taken of 10-12 neurons per animal at $63 \mathrm{X}$ magnification to count synapsin positive contacts, and images were taken at $40 \mathrm{X}$ magnification to examine neural morphology. In experiment 2, images were taken of 6-12 neurons per animal at $40 \mathrm{X}$ magnification for both counting synapsin positive contacts and examining neural morphology. Neurons were selected based on whether the somata were complete. When selecting neurons, if the somata were cut by the microtome when sections were sliced, then those neurons were not used. However, the neurons analyzed did not have complete dendrites because analysis of dendrites was restricted by the field of view of the confocal microscope. The confocal microscope allowed both red TH positive staining and green synapsin positive staining to be visualized at the same time. A stack of images taken along the z-plane (z-stack) was made for each neuron. The stack consisted of 22 images slicing the neuron from top to bottom at intervals of 1-1.5 $\mu \mathrm{m}$ determined by the confocal software based on the size of the neuron. These z-stacks were then converted to a series of tif file type images that could be analyzed using other software. 
MicroBrightfield's neurolucida software was used to recreate a z-stack from the confocal images of each neuron. A tracing was made of each neuron by first tracing around the cell body of each layer of the stack from top to bottom, and then tracing over the dendrites by matching the cursor size to the width of the dendrite and then following the dendrite through the stack (Figure 29). This created a 3-D reconstruction of the neuron (Figures 29-33). After tracing the neuron an asterisk marker was placed over each green immunstained synapsin dot in contact with the cell body or dendrite. This asterisks was sized once at the beginning of the study, by randomly selecting a green synapsin-labeled dot and matching the size of the asterisk to that dot. Also, when multiple terminals were close together creating what looked like one long terminal, markers were placed close together until all of the green-synpasin positive staining was covered. This allowed a count of the number of contacts of synapsin-labeled terminals either on the cell body or the dendrites to be made. The 3-D reconstructed neuron was rotated in $360^{\circ}$ and terminals that were not touching the neuron in all dimensions were eliminated, this procedure also ensured that each terminal was only being counted once. Asterisks appeared as small spheres in the 3-D reconstructed neuron. Once a reconstruction was complete the neurolucida software also automatically calculated dendrite mean length, quantity of primary dendrites, surface area of cell body, surface area of dendrites, volume of cell body, and number of dendritic nodes (bifurcations). The investigator was unaware of the particular treatment when analyzing all neurons.

Statistical Analysis: Results from all neurons per animal (6-12) were averaged together for each animal and these numbers were used in statistical analyses. All data from 
experiment 1 were evaluated for the effect of season by unpaired t-tests using Graphpad's Prism software. All data from experiment 2 were evaluated by two-way ANOVA using Jandel's SigmaStat software. Statistical significance was set at $\mathrm{P}<0.05$ for all analyses.

Table 1: Treatment Groups for Animals in Experiment 2

\begin{tabular}{|l|c|c|c|c|}
\hline Animals & $\begin{array}{l}\text { Estrogen } \\
\text { Treatment }\end{array}$ & $\begin{array}{l}\text { T4 } \\
\text { Treatment }\end{array}$ & $\begin{array}{l}\text { THX } \\
\text { animals }\end{array}$ & $\begin{array}{l}\text { Intact } \\
\text { Animals }\end{array}$ \\
\hline $\mathrm{N}=3$ & + & - & - & + \\
\hline $\mathrm{N}=3$ & - & - & - & + \\
\hline $\mathrm{N}=3$ & + & + & + & - \\
\hline $\mathrm{N}=2$ & - & + & + & - \\
\hline $\mathrm{N}=3$ & + & - & + & - \\
\hline $\mathrm{N}=3$ & - & - & + & - \\
\hline
\end{tabular}

+ Received treatment

- Did not receive treatment

\begin{tabular}{|c|c|c|c|c|}
\hline & $\begin{array}{l}\text { B/w Nov. } 14 \text { and Dec. } \\
12,1996, \text { ewes } T H X \text {, } \\
\text { half received } T_{4}\end{array}$ & & $\begin{array}{l}\mathrm{T}_{4} \text { treatment in half----- } \\
\text { THX animals }\end{array}$ & \\
\hline 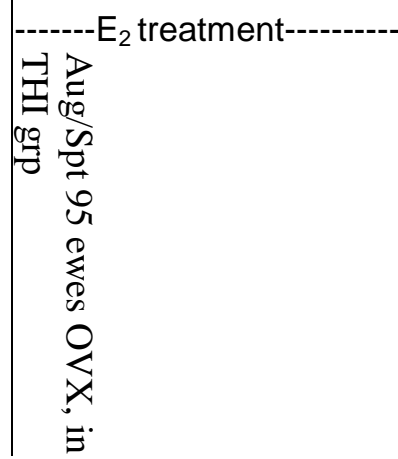 & 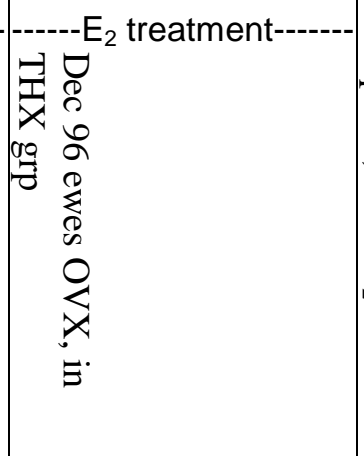 & $\begin{array}{l}8 \\
0 \\
0 \\
0 \\
0 \\
0 \\
0 \\
0 \\
0\end{array}$ & 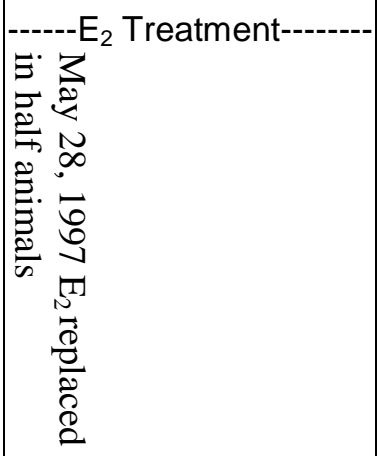 & 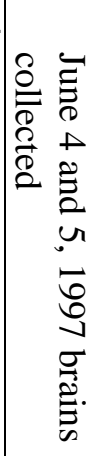 \\
\hline
\end{tabular}

Figure 1. Timeline of treatments given to animals in experiment 2 


\section{CHAPTER THREE: RESULTS}

Experiment 1: Breeding Season vs. Non-Breeding Season

\section{Cell Body}

No significant change $(\mathrm{P}>0.05)$ in cell body volume occurred between the breeding season and the non-breeding season (Figure 2). The mean volume for cell bodies of neurons in the breeding season was $7725 \pm 859 \mu \mathrm{m}^{3}$, and the mean volume for cell bodies of neurons in the non-breeding season was $7538 \pm 663 \mu \mathrm{m}^{3}$.

Dendrites

A significant difference $(\mathrm{P}<0.0001)$ in dendrite mean length was found (Figure 3$)$. The dendrite mean length increased from a mean of $53.3 \pm 5.1 \mu \mathrm{m}$ in the breeding season to a mean of $127.2 \pm 7.5$ during the non-breeding season. A similar change in mean surface area of dendrites was seen $(\mathrm{P}<0.001$; Figure 5). The mean surface area increased from $693 \pm 47 \mu \mathrm{m}^{2}$ to $1566 \pm 149 \mu \mathrm{m}^{2}$ with the transition from breeding season to nonbreeding season. Also with the increase in mean length and mean surface area of dendrites a significant change $(\mathrm{P}<0.0028)$ in mean bifurcation number occurred (Figure 4). The mean number of bifurcations increased from $0.32 \pm 0.15$ during the breeding season to $1.3 \pm 0.21$ during the non-breeding season. However, no change in primary dendrite number was observed ( $\mathrm{P}>0.05$; Figure 6$)$. The mean number of primary dendrites per neuron in the breeding season was $2.5 \pm 0.24$ while the mean number of primary dendrites per neuron in the non-breeding season was $2.9 \pm 0.15$.

\section{Contacts on Neurons}

The total number of terminals on the neurons did change significantly $(\mathrm{P}<0.0377)$ between the breeding season and non-breeding season (Figure 7). The terminals on the breeding season neurons, $45.2 \pm 2.3$, were significantly less than the 
terminals on the non-breeding season neurons, $56.6 \pm 4.7$. This increase in contacts on the neurons was observed on the dendrites $(\mathrm{P}<0.012$; Figure 8$)$, but not on the somas $(\mathrm{P}<0.05$; Figure 9). The terminals increased on the dendrites from $18.2 \pm 2.0$ during the breeding season to $28.0 \pm 2.7$ during the non-breeding season, and the contacts on the somas were $26.9 \pm 1.78$ during the breeding season and $28.6 \pm 2.9$ during the nonbreeding season. Density of terminals on neurons was also measured by dividing the number of contacts by the surface area of either the dendrites or the cell bodies. No significant change was found in either the density on the soma $(\mathrm{P}>0.05$; Figure 10$)$ or the density on the dendrites $(\mathrm{P}>0.05$; Figure 11) 
Experiment 2: Changes in Thyroid Hormone

Cell Body

No significant change $(\mathrm{P}>0.05)$ in cell body surface area occurred when animals were thyroidectomized, treated with T4, or left intact (Figure 14).

$\underline{\text { Dendrites }}$

Mean lengths of dendrites were significantly $(\mathrm{P}<0.05)$ longer in intact and T4treated animals than in thyroidectomized animals regardless of the estrogen treatment (Figure 15). Estrogen treatment had no significant effect on dendrite mean length. The mean for intact animals was $99.3 \pm 7.9 \mu \mathrm{m}$ and for T4 treated animals was $120 \pm 8.9 \mu \mathrm{m}$ verses $68.2 \pm 7.9 \mu \mathrm{m}$ for thyroidectomized animals. There was not a significant difference between $\mathrm{T} 4$ treated animals and intact animals $(\mathrm{P}>0.05)$. There was an increase in mean surface area of dendrites seen in T4 treated animals compared to the thyroidectomized group $(\mathrm{P}<0.05)$, but this increase was not seen in the intact group compared to the thyroidectomized group $(\mathrm{P}>0.05)$ (Figure 16). The mean for the T4 group was $1117 \pm 103 \mu \mathrm{m}^{2}$ compared to $954.4 \pm 103 \mu \mathrm{m}^{2}$ for the THX group. The presence of estrogen had no significant effect $(\mathrm{P}>0.05)$ on mean surface area of the dendrites. The mean number of bifurcations did not significantly change $(\mathrm{P}>0.05)$ regardless of thyroid treatment or estrogen treatment (Figure 17). The mean number of primary dendrites also did not significantly change $(\mathrm{P}>0.05)$ with thyroid treatment or estrogen treatment (Figure 18).

\section{Contacts on Neurons}

There was not a significant change $(\mathrm{P}>0.05)$ in total contact number on neurons (both dendrites and somata) with changes in thyroid hormone or changes in estrogen treatment (Figure 19). There was a significant change $(\mathrm{P}<0.05)$ in contacts on dendrites 
when comparing the intact group verses the thyroidectomized group in the absence of estrogen, and there was a difference mean of 21.5 contacts (Figure 20). However, there was no significant change $(\mathrm{P}>0.05)$ in contacts on the cell body with thyroid treatment or estrogen treatment (Figure 21). There was also not a significant change $(\mathrm{P}>0.05)$ in density of contacts on dendrites or cell body with changes in thyroid hormone or estrogen treatment (Figure 22 and Figure 23). 


\section{Volumes of Cell Body}

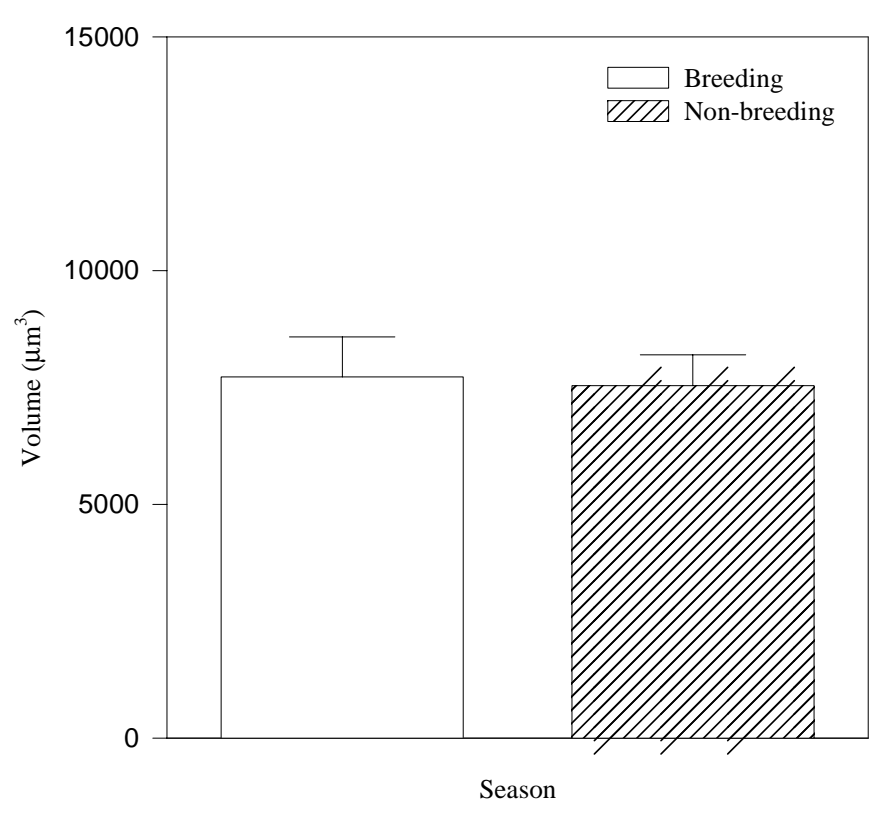

Figure 2. Volumes of Cell Body Breeding Season Vs. Non-Breeding Season $(\mathrm{P}>0.05)$

Mean Length of Dendrites

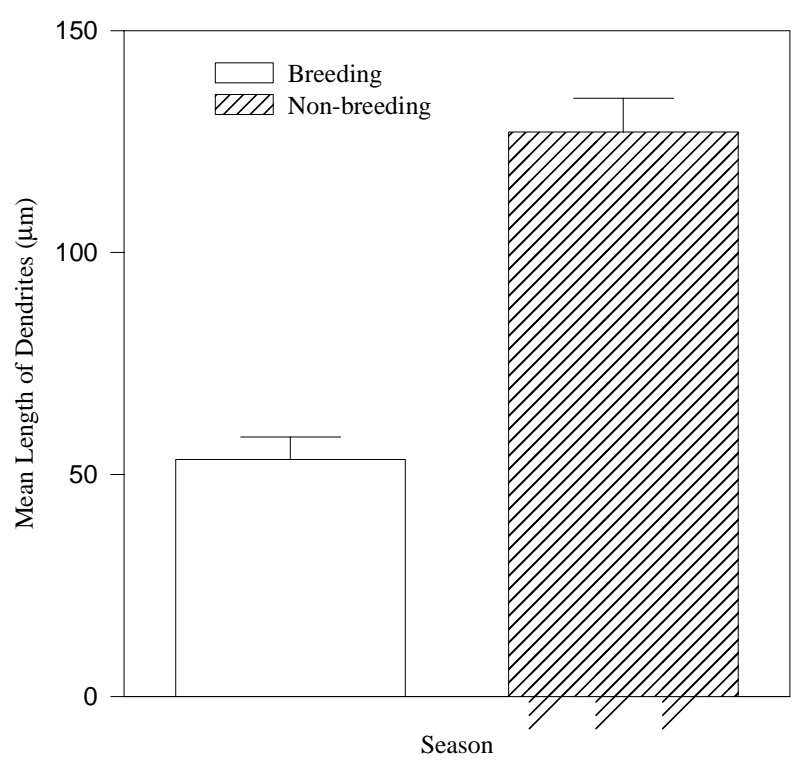

Figure 3. Mean Length of Dendrites Breeding Season vs. Non-breeding Season $(\mathrm{P}<0.0001)$ 
Mean number of Bifurcations (Nodes) per neuron

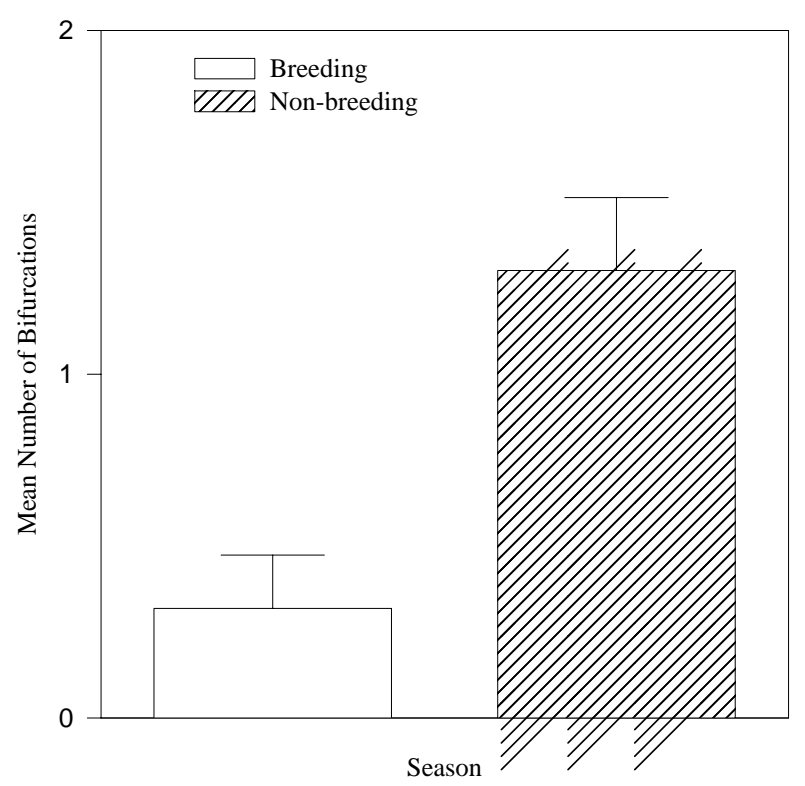

Figure 4. Mean Number of Bifurcations in Dendrites Breeding Season vs. Non-Breeding Season $(\mathrm{P}<0.001)$

\section{Mean Surface Area}

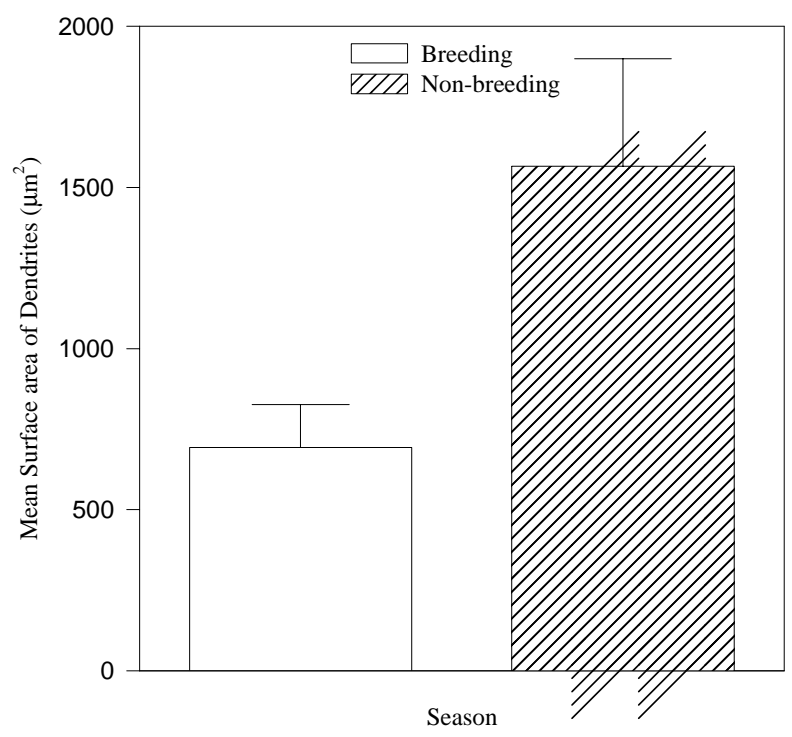

Figure 5. Mean Surface Area of Dendrites Breeding Season vs. Non-Breeding Season $(\mathrm{P}<0.0028)$ 
Number of Primary Dendrites

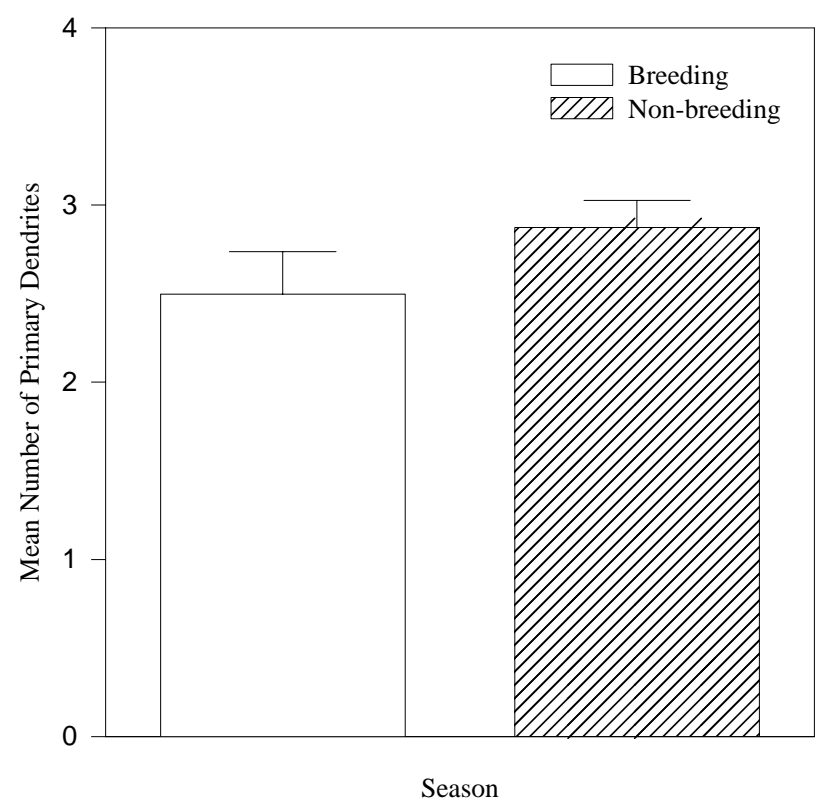

Figure 6. Number of Primary Dendrites on Neurons in Breeding Season vs. NonBreeding Season $(\mathrm{P}>0.05)$

Total Number of Contacts on Neuron

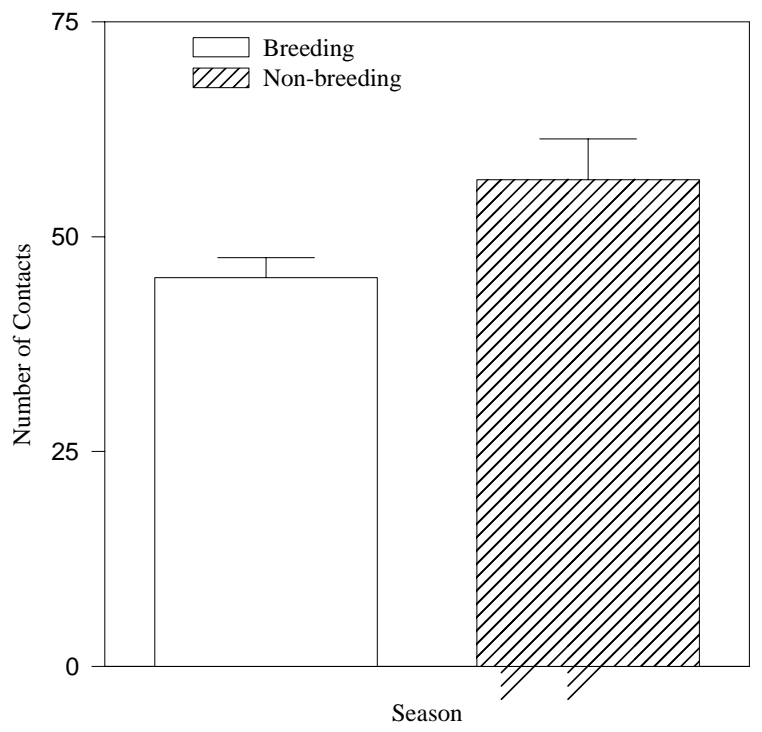

Figure 7. Number of Total Terminals on Neurons in the Breeding Season vs. NonBreeding Season $(\mathrm{P}<0.037)$ 


\section{Number of Contacts on Dendrite}

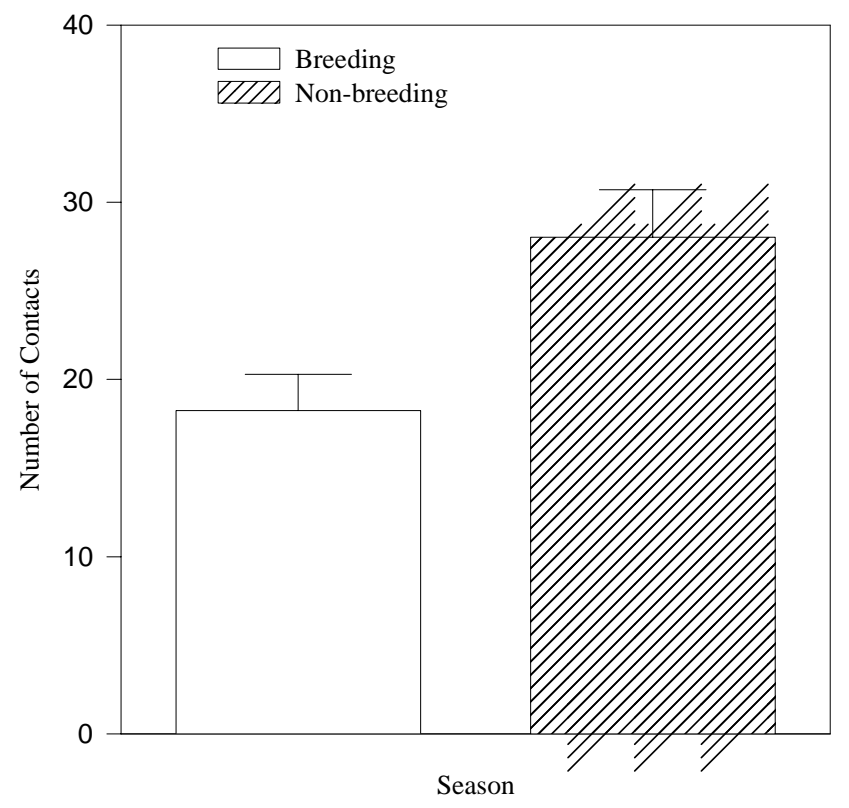

Figure 8. Number of Terminals on Dendrites during Breeding Season vs. Non-Breeding Season $(\mathrm{P}<0.012)$

Number of Contacts on Cell Body

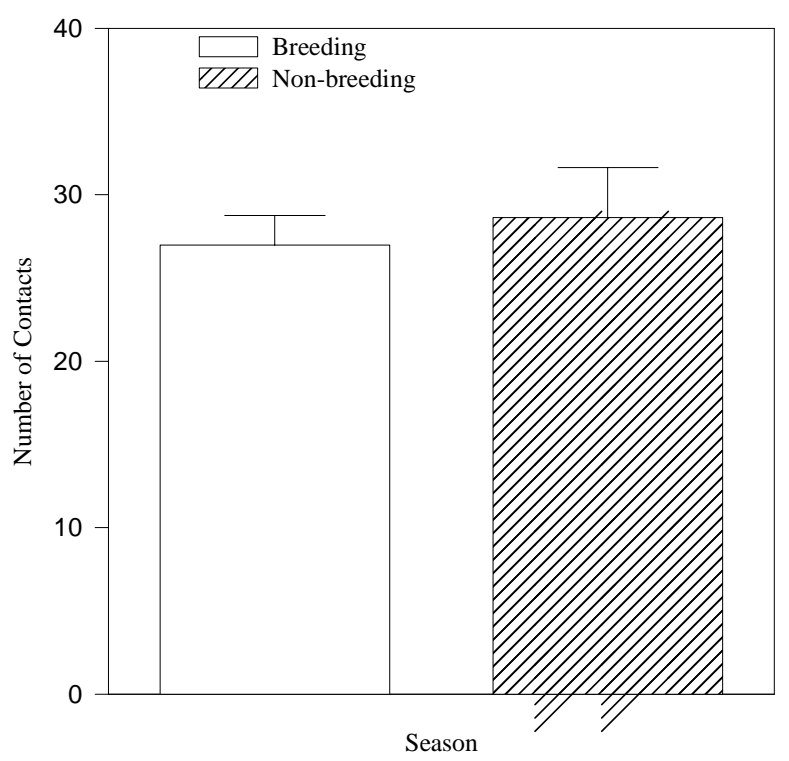

Figure 9. Number of Terminals on Cell Body in Breeding Season vs. Non-Breeding Season $(\mathrm{P}>0.05)$ 


\section{Contact Density on Cell Body}

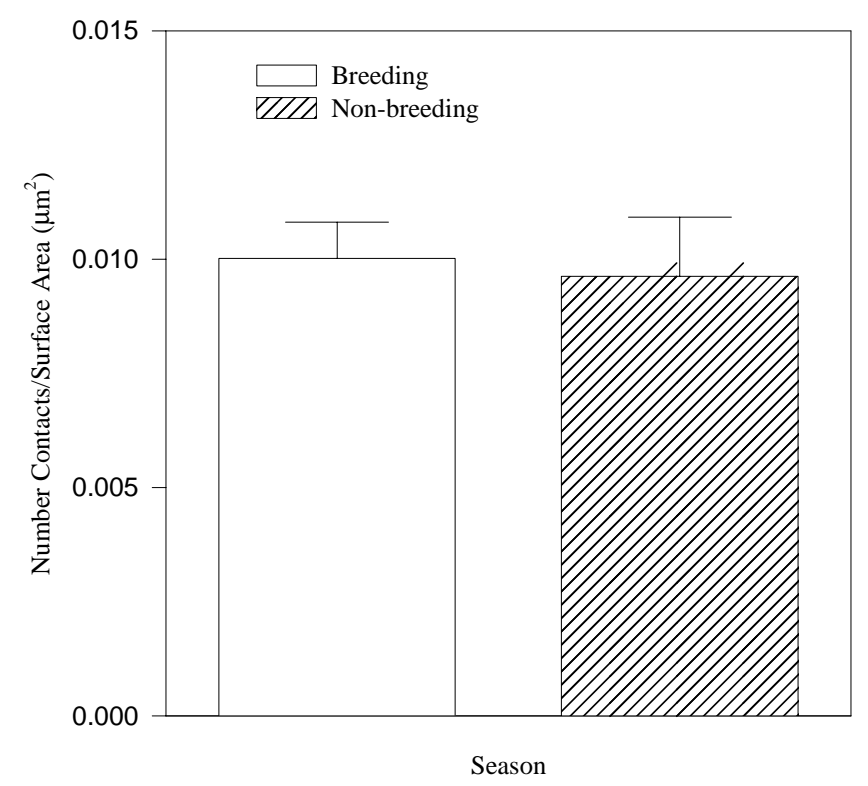

Figure 10. Terminal Density on Cell Body in Breeding Season vs. Non-Breeding Season $(\mathrm{P}>0.05)$

\section{Contact Density on Dendrite}

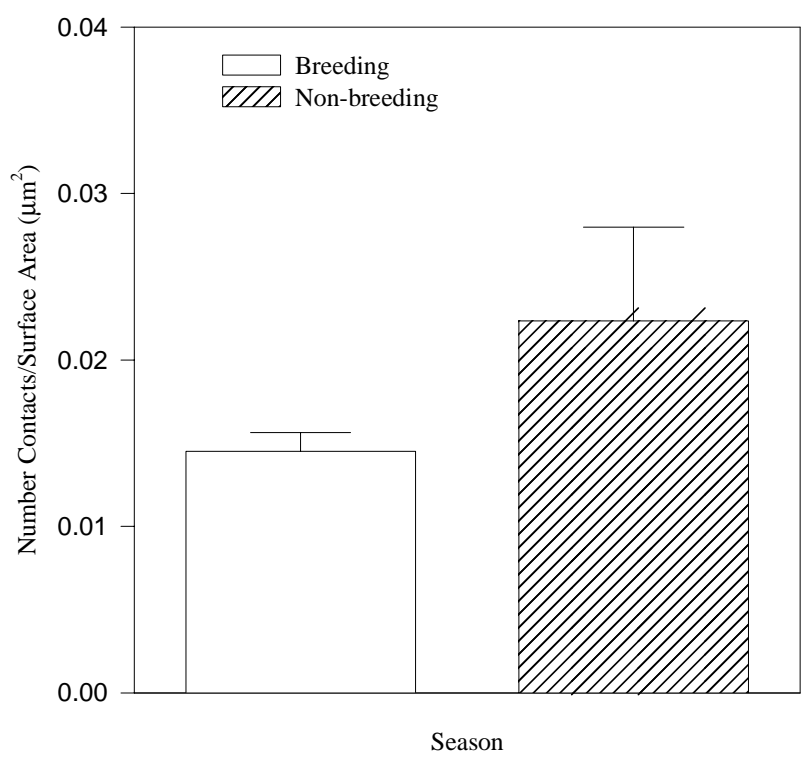

Figure 11. Terminal Density on Dendrite in Breeding Season vs. Non-Breeding Season $(\mathrm{P}>0.05)$ 


\section{Total Endings In Section}

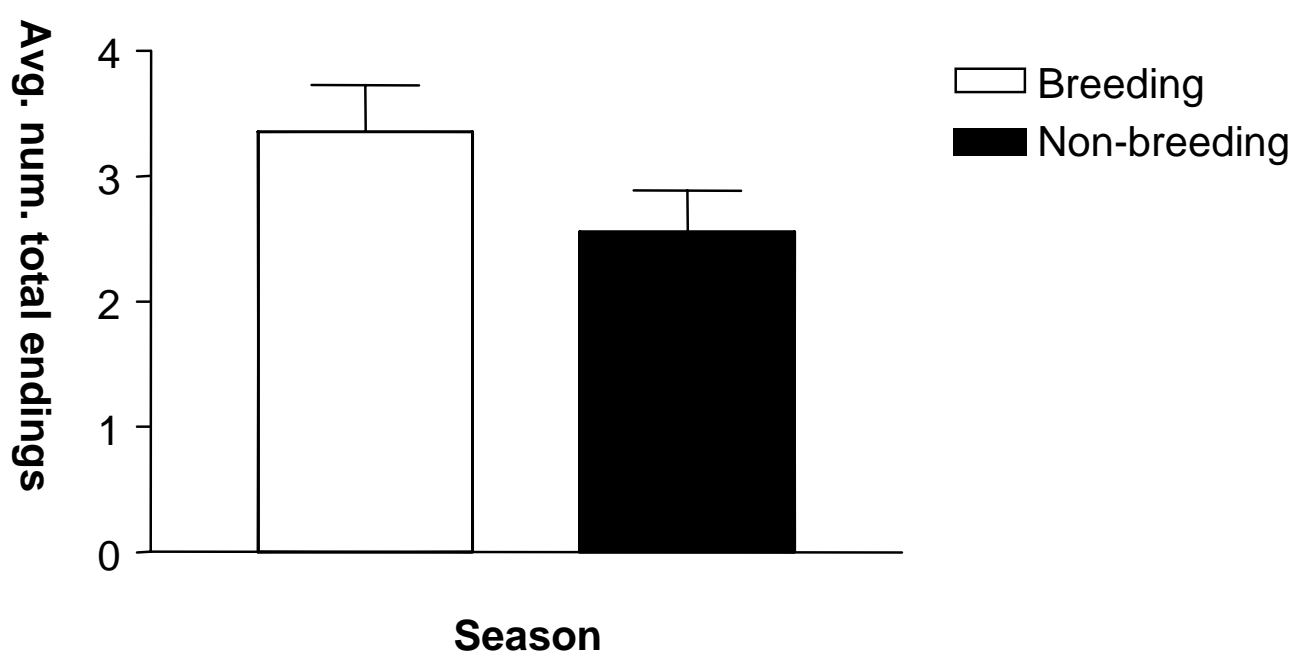

Figure 12. The Average of the Total Number of Endings of Dendrites that were counted at the Top and Bottom of the z-stacks $(\mathrm{P}>0.05)$

Top-Bottom of Section

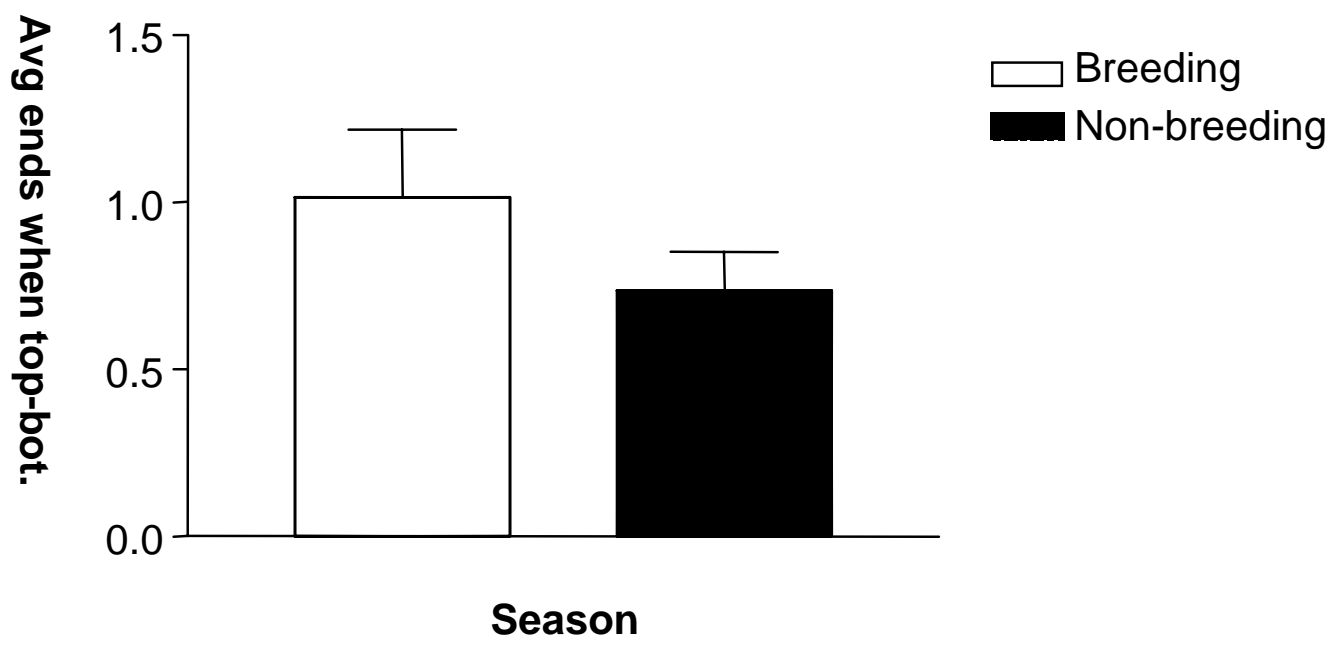

Figure 13. The Average of the Number of Endings of Dendrites when Subtracting the Number Taken from the Top Section from the Number Taken from the Bottom Section of the $\mathrm{z}$-stacks $(\mathrm{P}>0.05)$ 


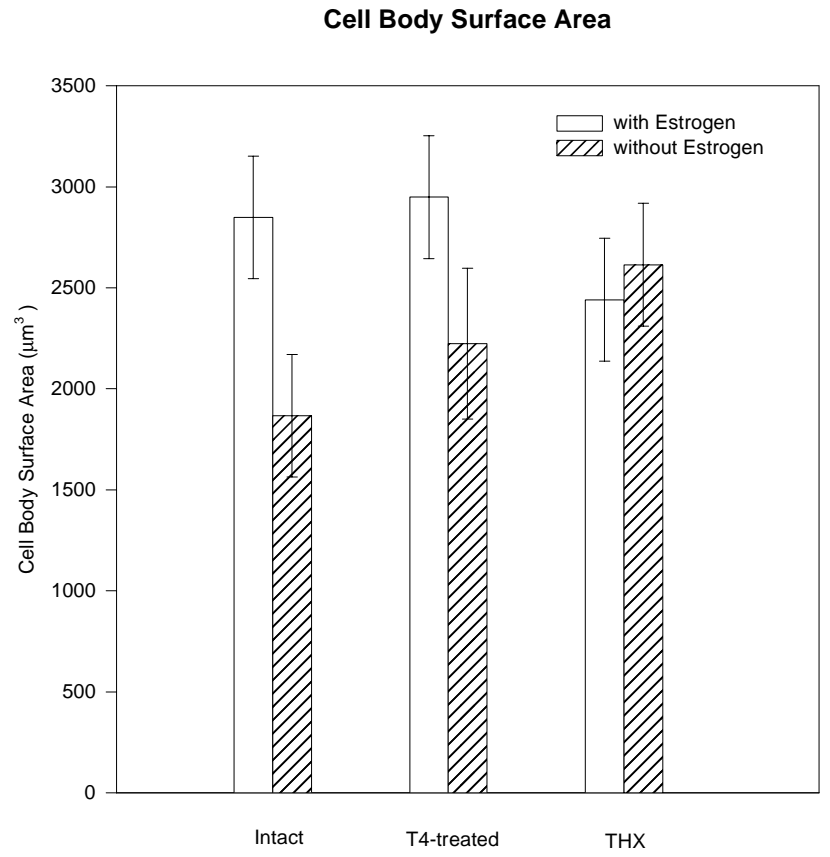

Figure 14. Cell Body Surface Area in Thyroid and Estrogen Treated Animals $(\mathrm{P}>0.05)$

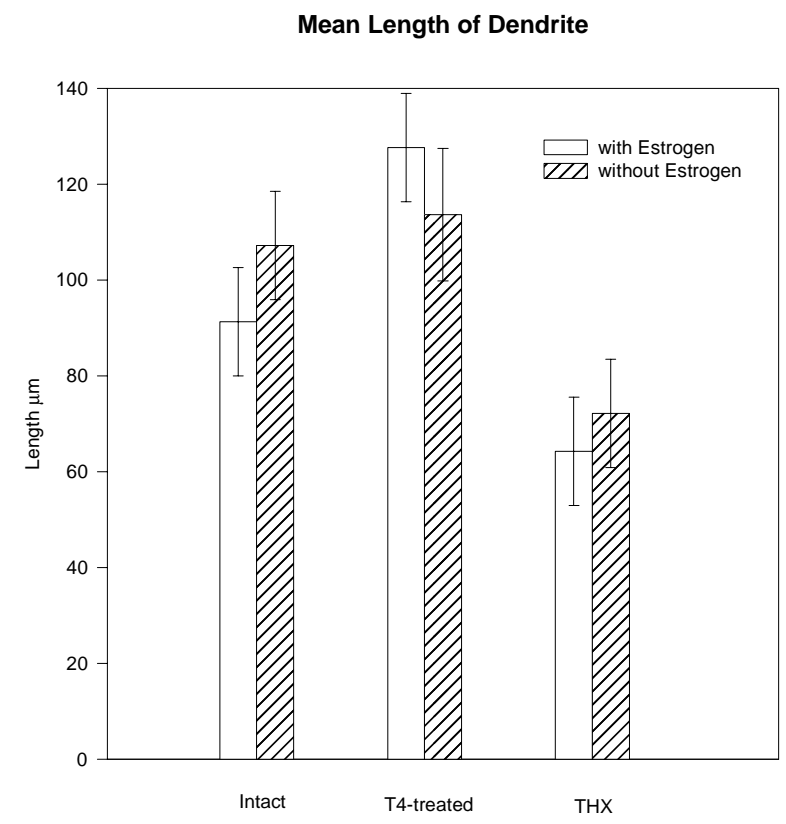

Figure 15. Mean Length of Dendrites in Thyroid and Estrogen Treated Animals $(\mathrm{P}<0.05)$ 


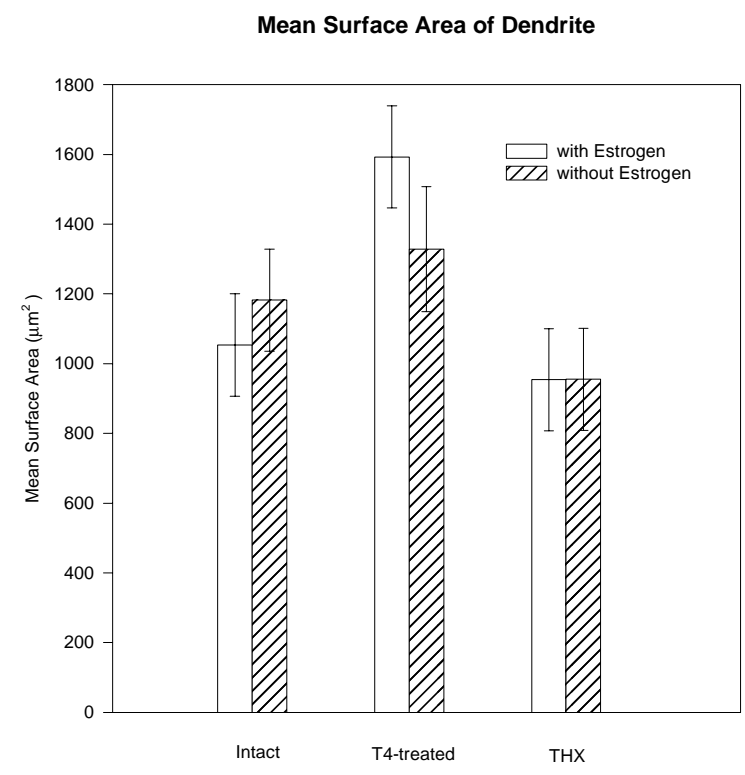

Figure 16. Mean Surface Area of Dendrites in Thyroid and Estrogen Treated Animals $(\mathrm{P}<0.05$ in $\mathrm{T} 4$ vs. THX)

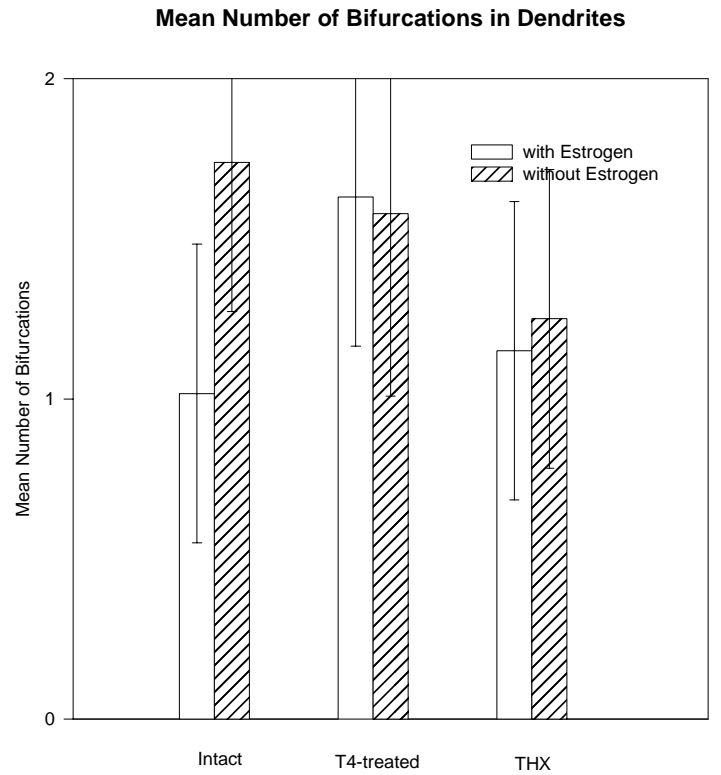

Figure 17. Mean Number of Bifurcations in Thyroid and Estrogen Treated Animals $(\mathrm{P}>0.05)$ 


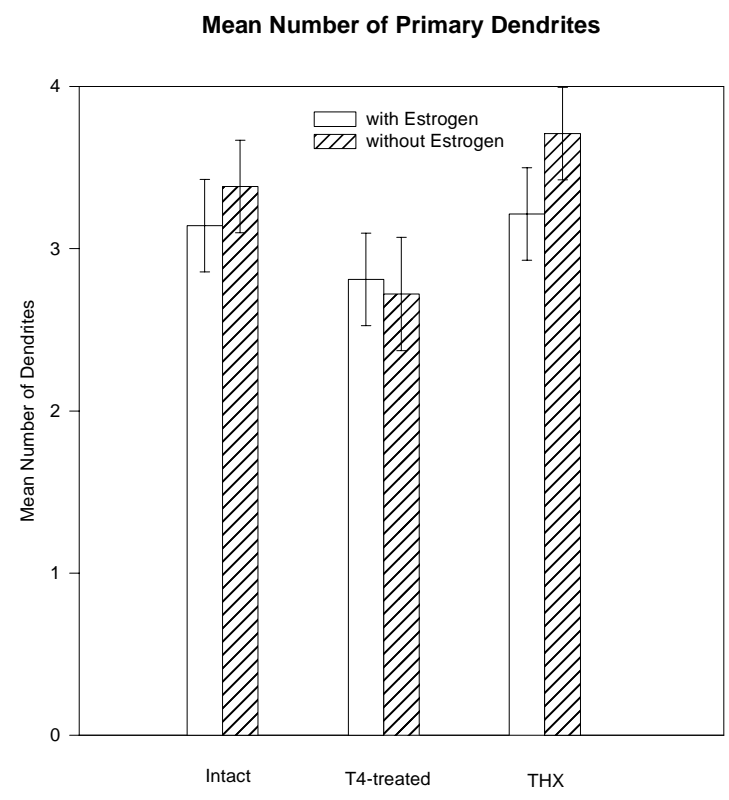

Figure 18. Mean Number of Primary Dendrites per Neuron in Thyroid and Estrogen Treated Animals $(\mathrm{P}>0.05)$

Total Number of Contacts

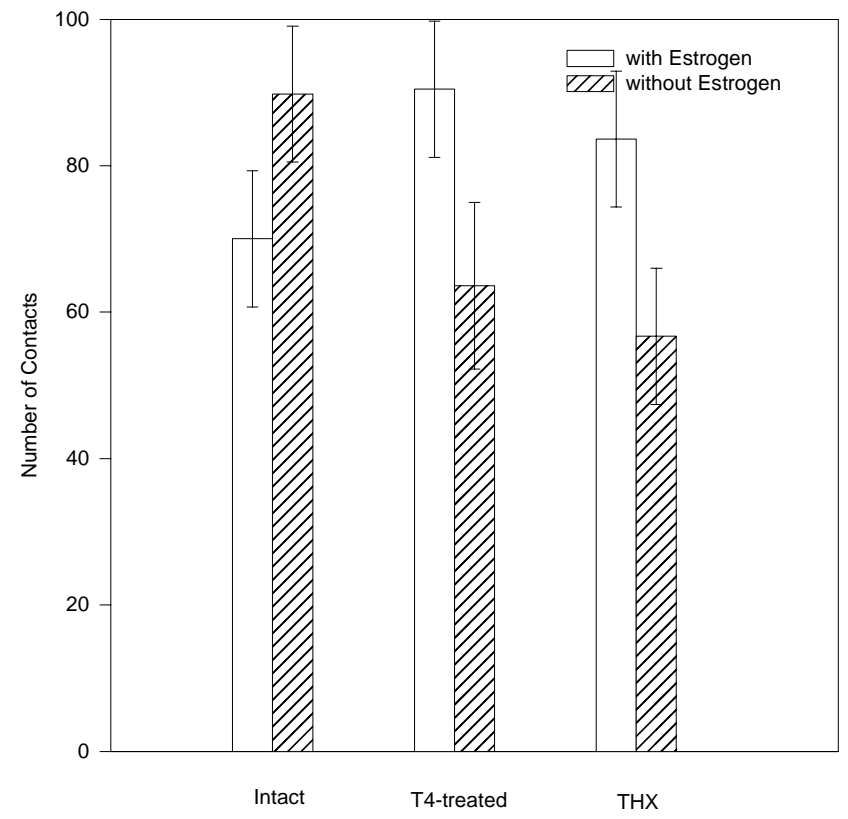

Figure 19. Total Number of Contacts on Neurons in Thyroid and Estrogen Treated Animals $(\mathrm{P}>0.05)$ 


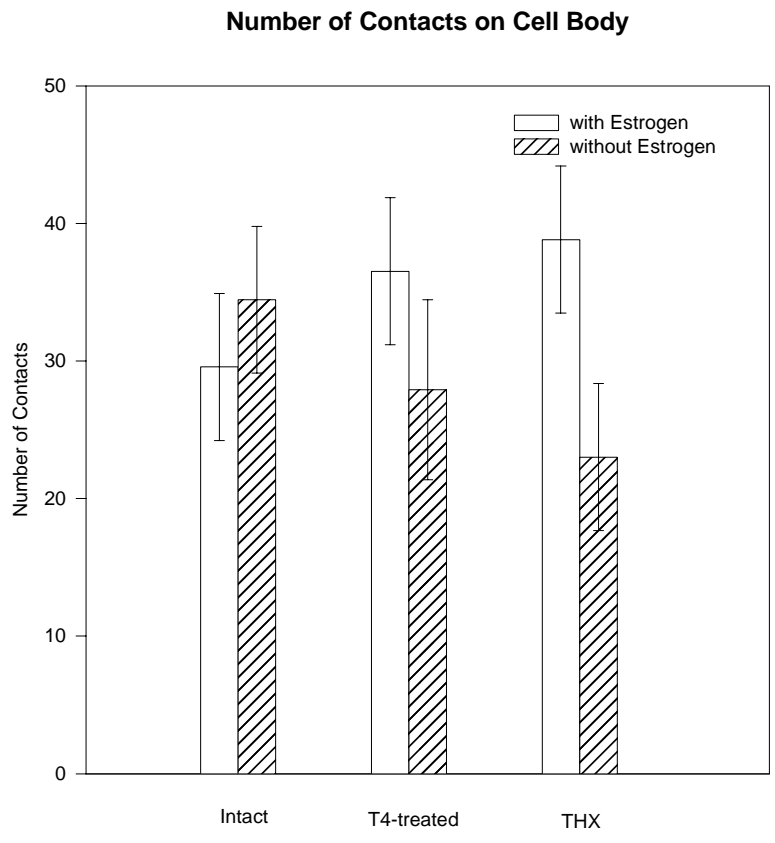

Figure 20. Number of Contacts on Cell Body of Neurons in Thyroid and Estrogen Treated Animals $(\mathrm{P}<0.05$ in THI-E vs. THX-E)

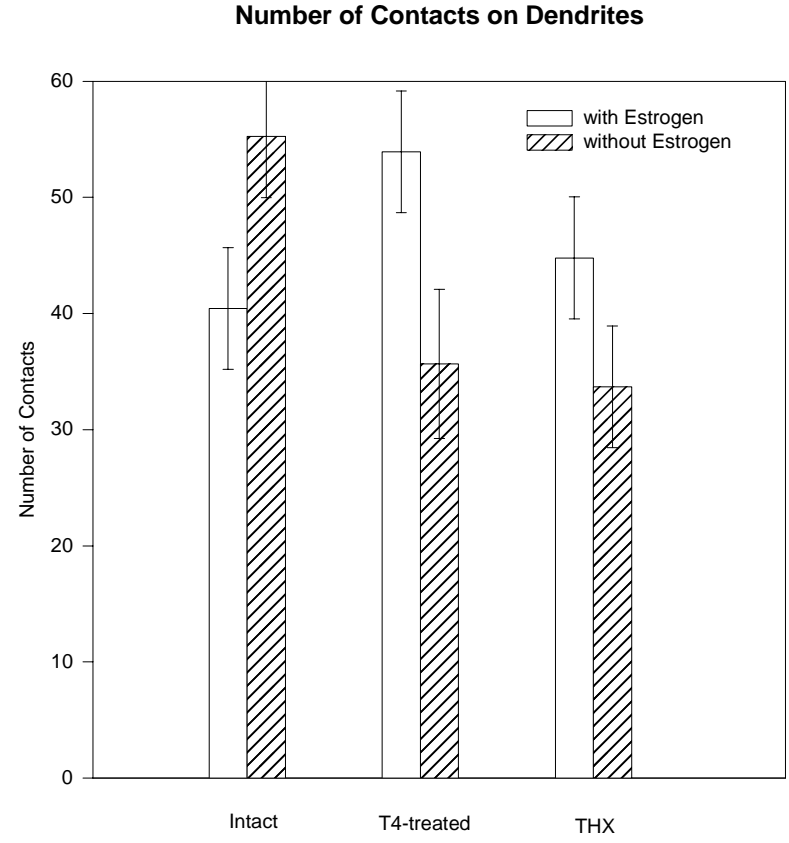

Figure 21. Number of Contacts on Dendrites of Neurons in Thyroid and Estrogen Treated Animals $(\mathrm{P}>0.05)$ 


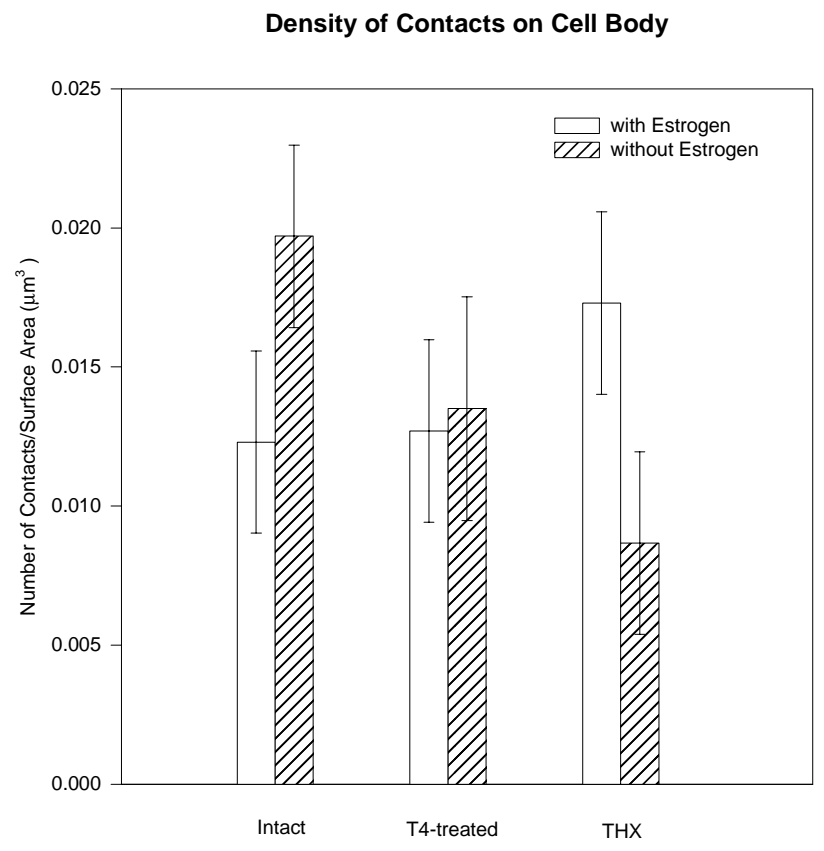

Figure 22. Density of Contacts on Cell Body of Neurons in Thyroid and Estrogen Treated Animals $(\mathrm{P}>0.05)$

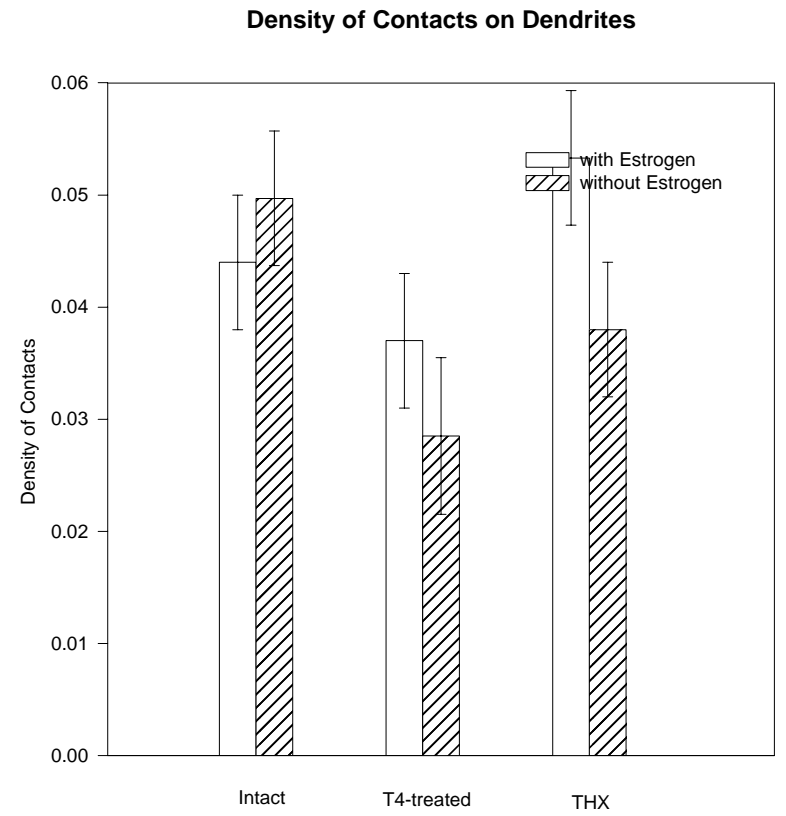

Figure 23. Density of Contacts on Dendrites of Neurons in Thyroid and Estrogen Treated Animals $(\mathrm{P}>0.05)$ 


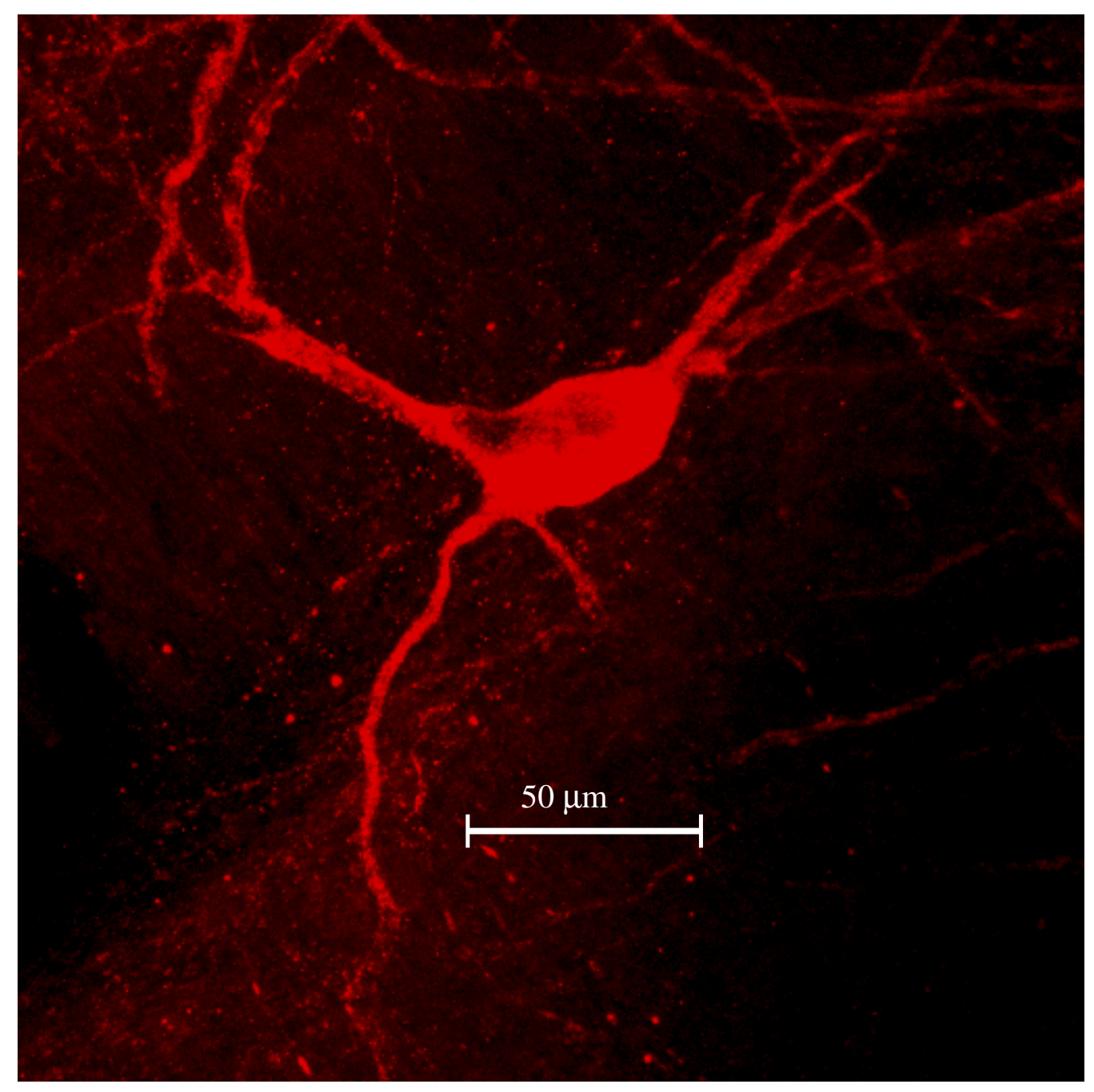

Figure 22. Neuron from a Noon-Breeding Season Animal 


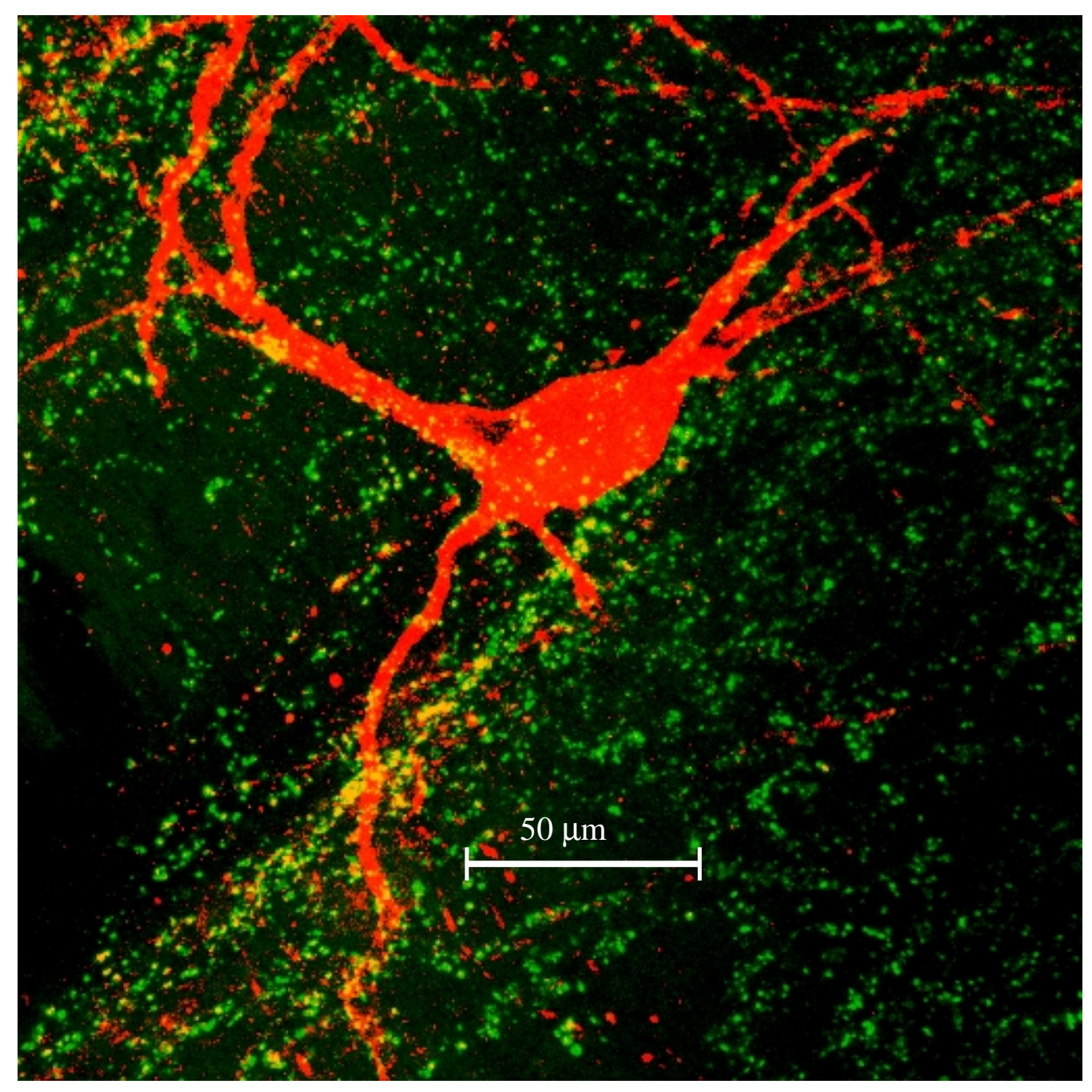

Figure 23. Neuron with Synapsin Staining from a Non-Breeding Season Animal 


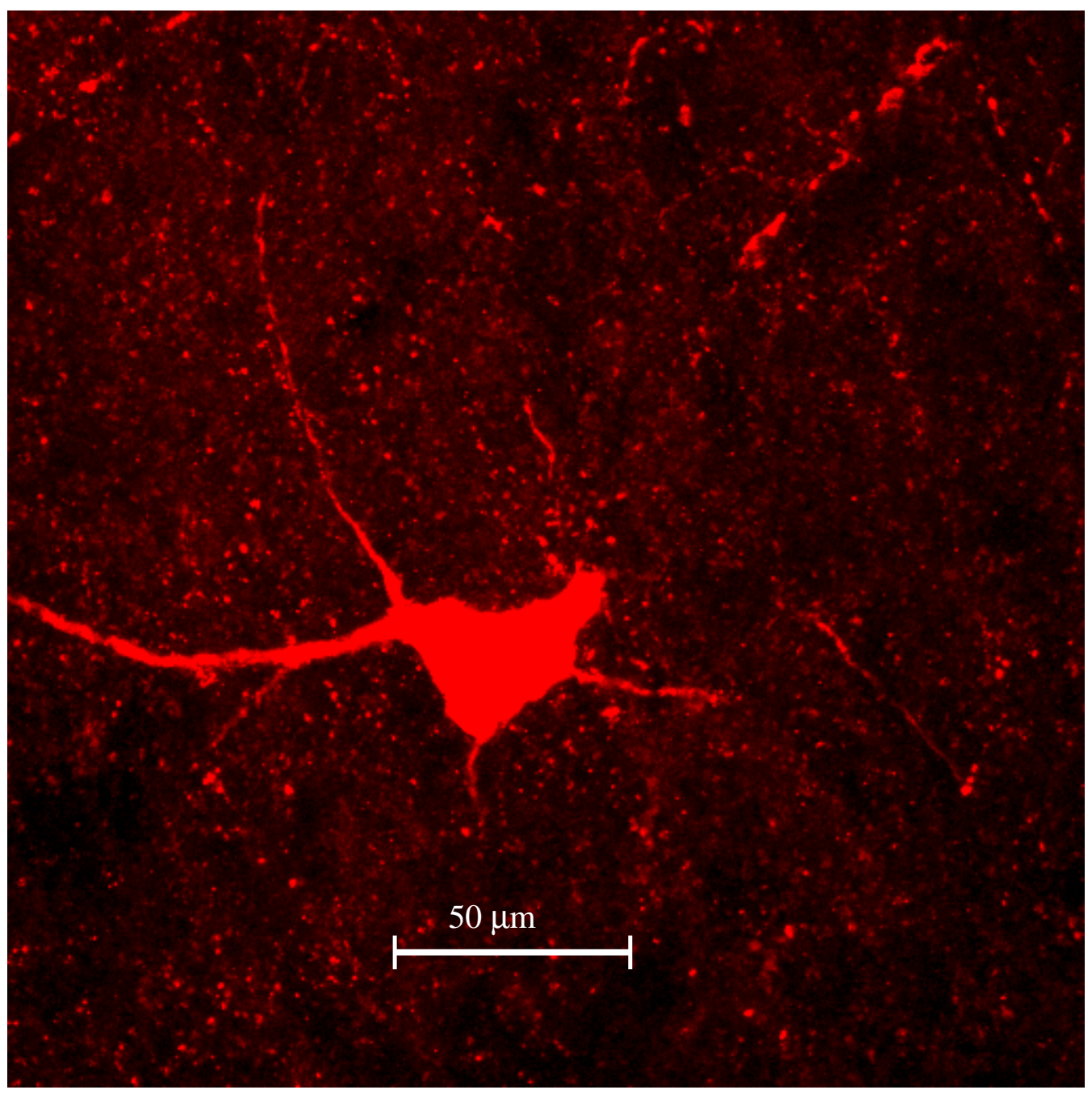

Figure 24. Neuron from a Breeding Season Animal 


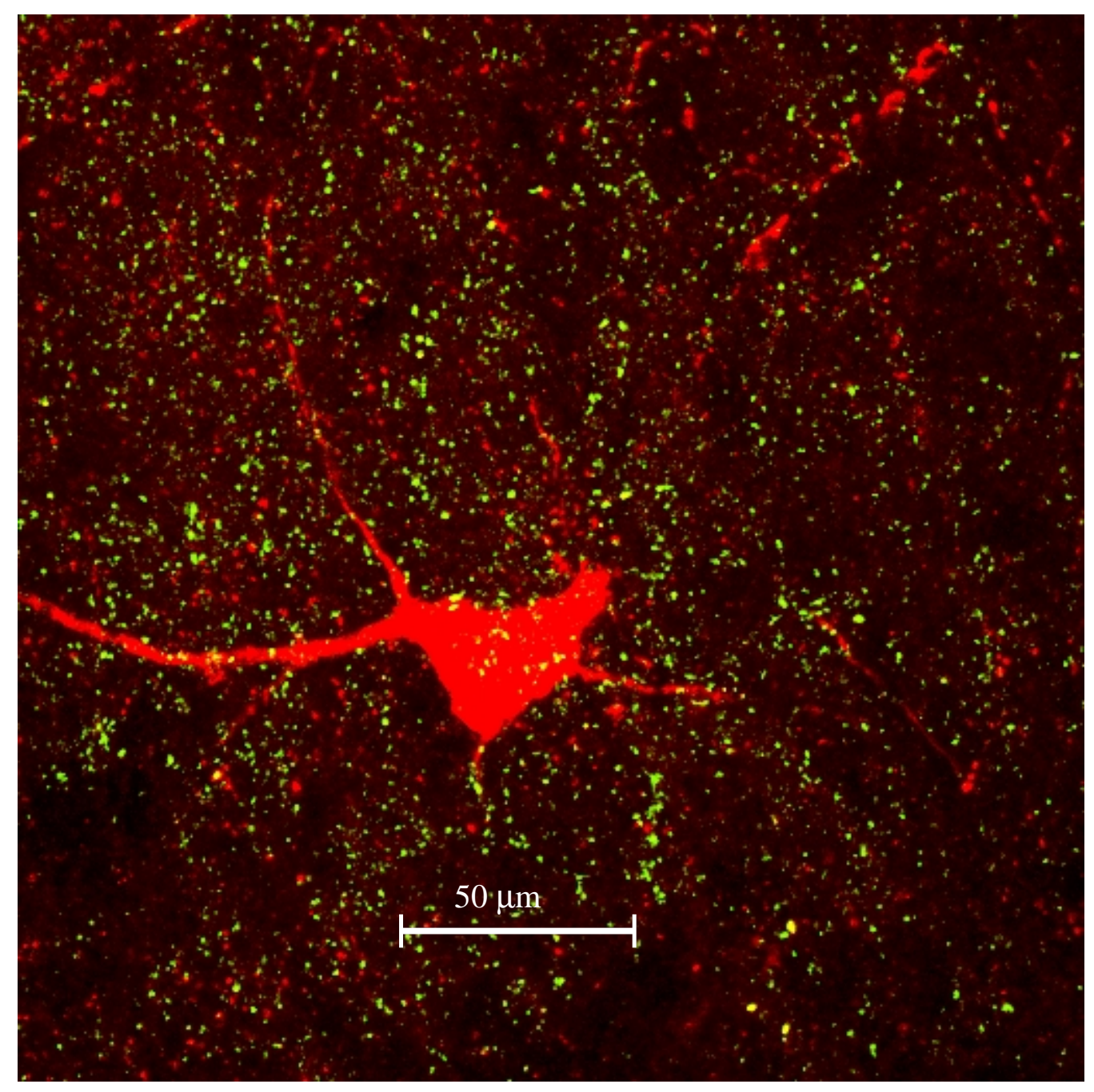

Figure 25. Neuron from a Breeding Season Animal with Synapsin Staining 


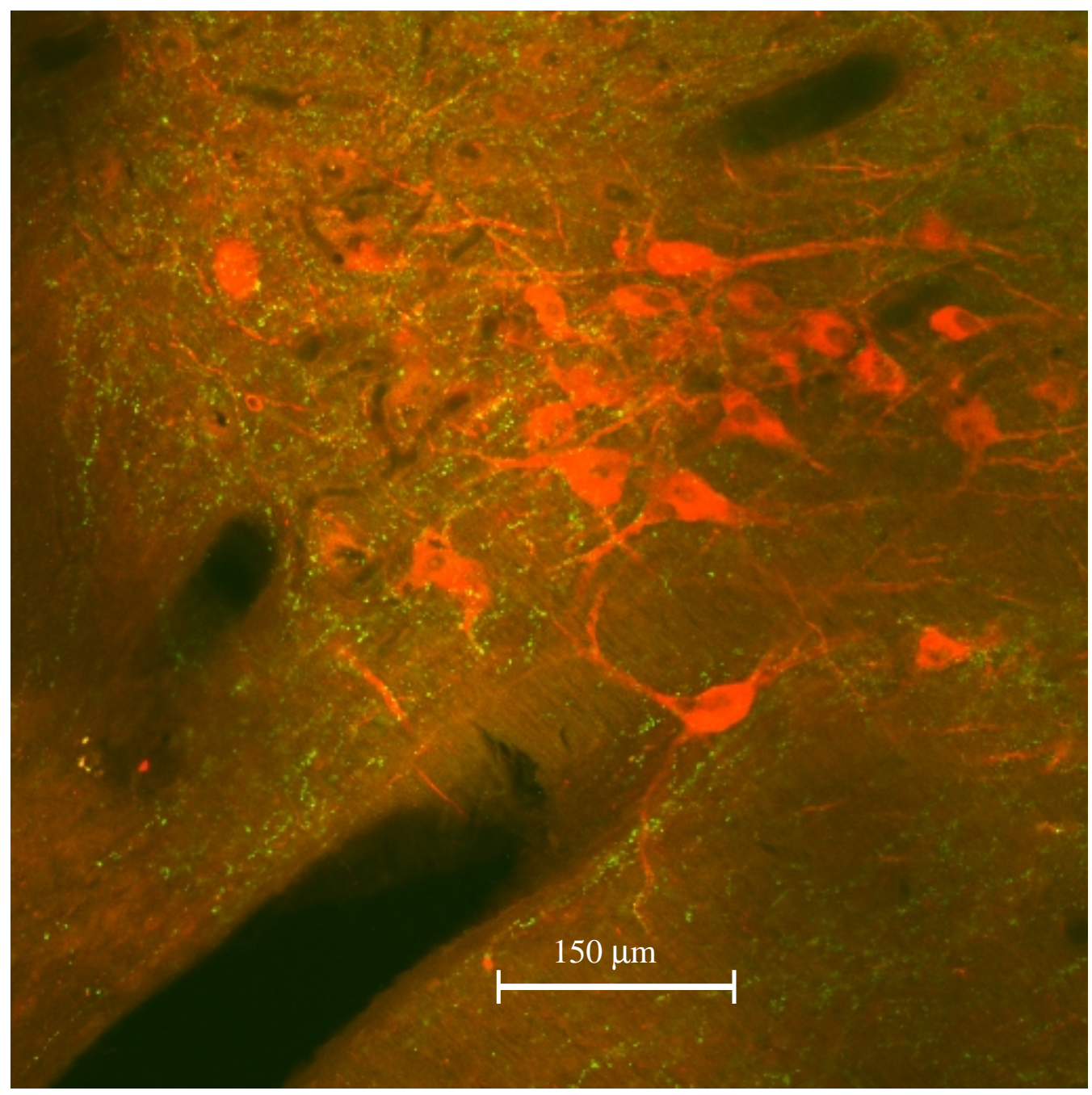

Figure 26. A15 Dopaminergic Nucleus and Synapsin at 20X Magnification 


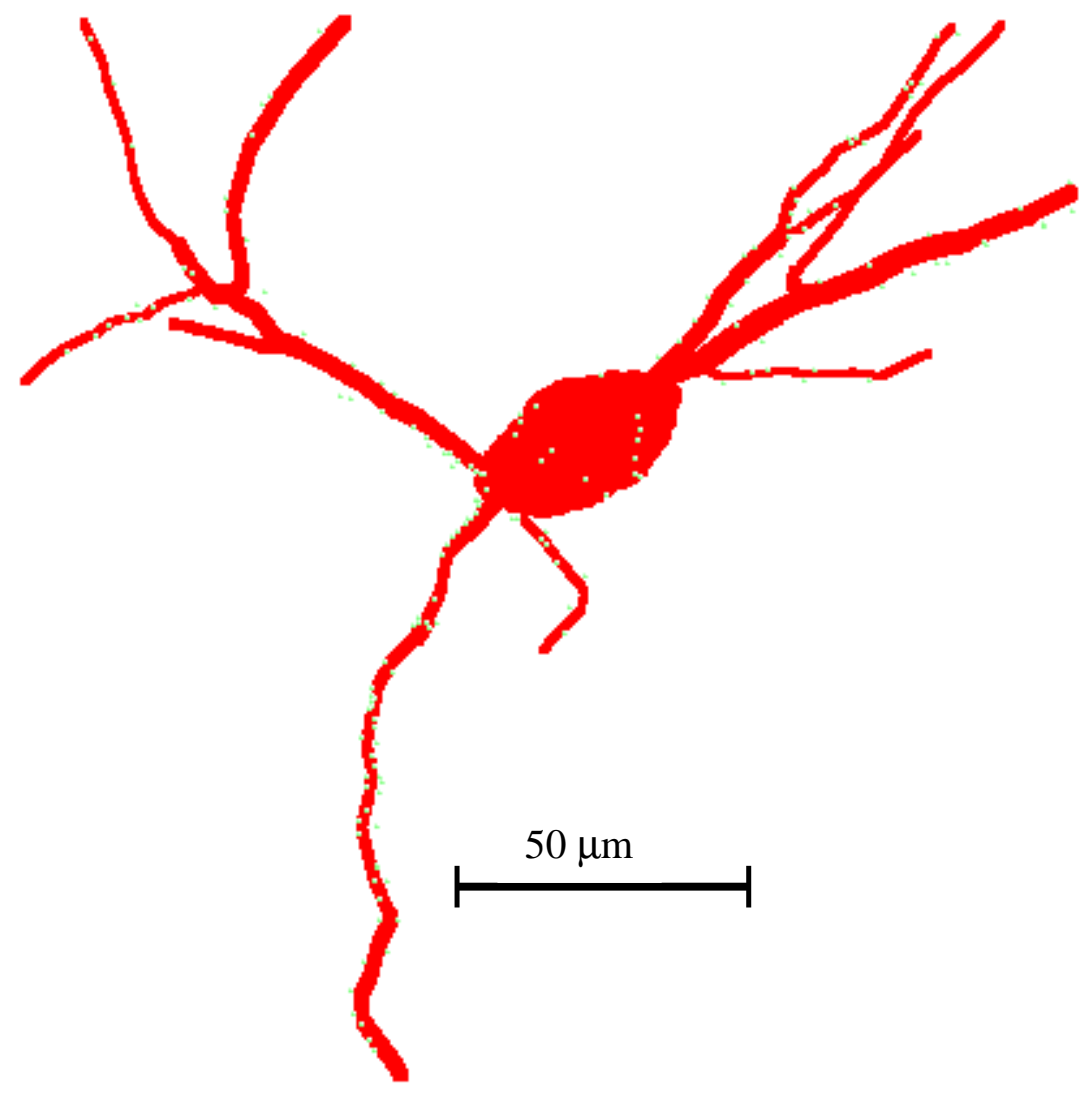

Figure 27. Neurolucida Tracing of A15 Neuron from an Anestrous Animal, (Green dots represent synapsin) 


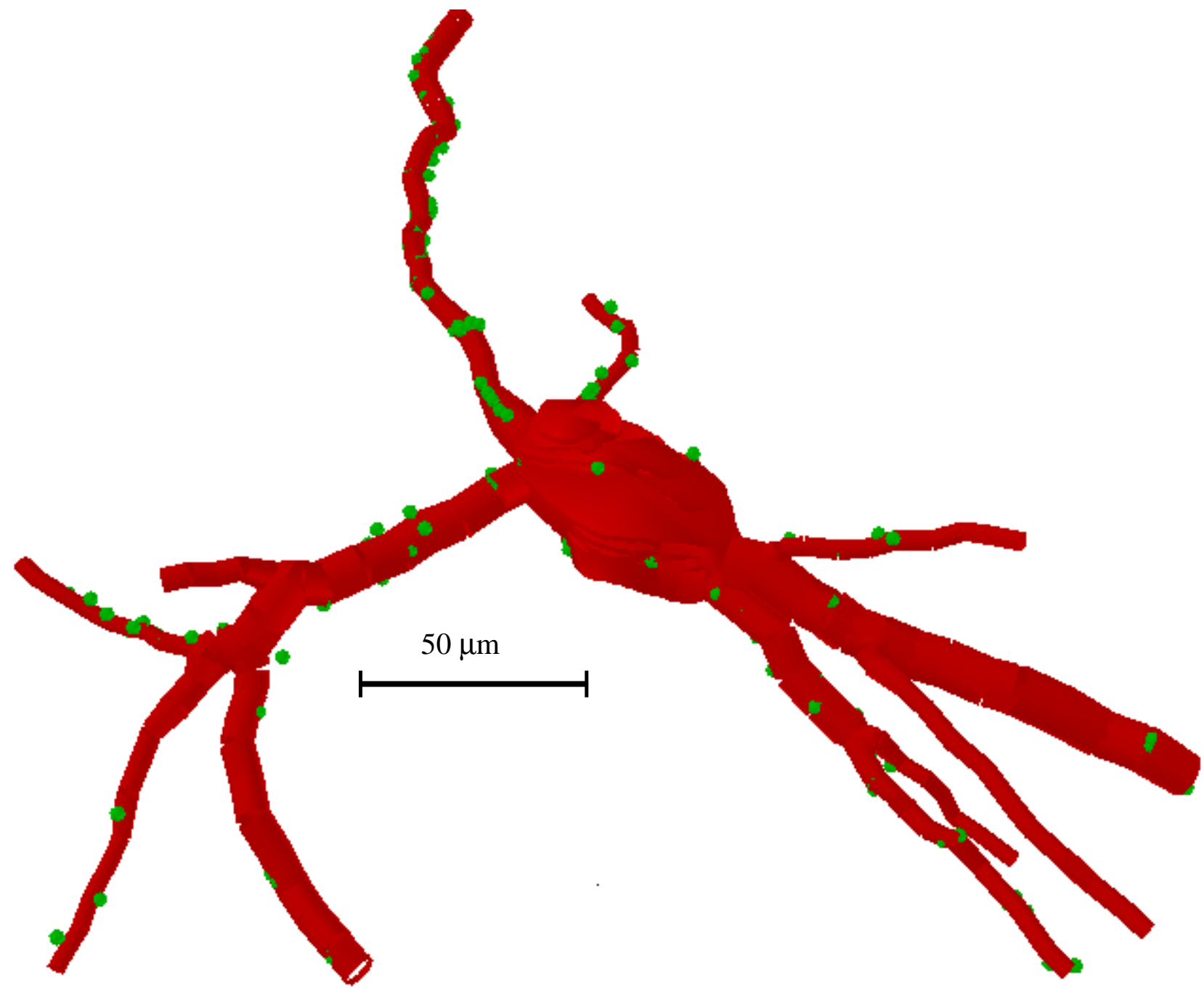

Figure 28. Neurolucida 3-D Reconstruction of Neuron from Anestrous Animal (Tilted at a $45^{\circ}$ angle) 


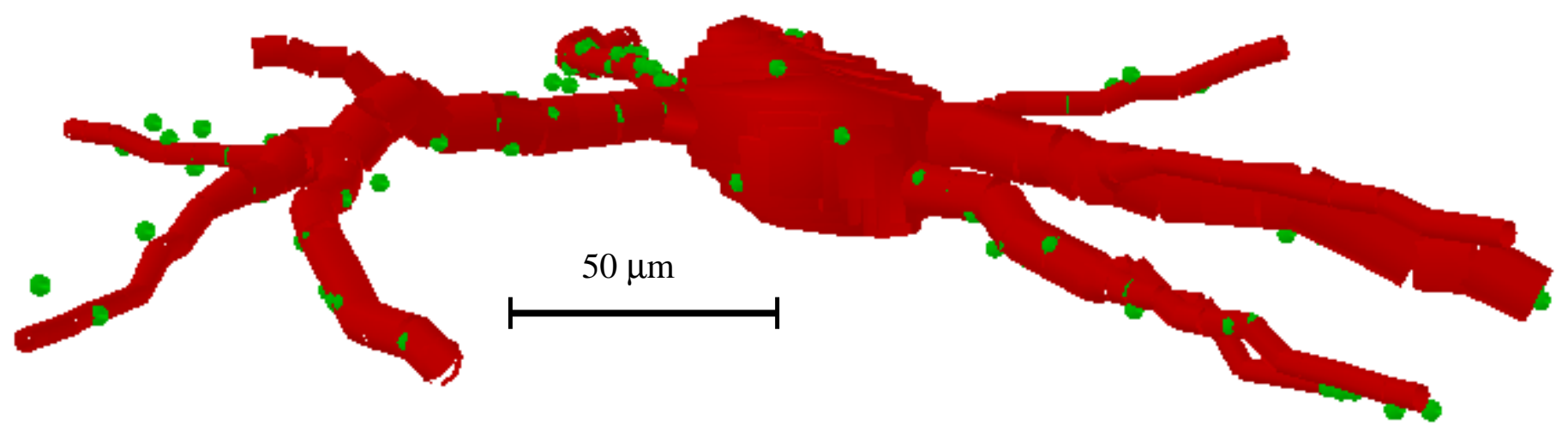

Figure 29. Neurolucida 3-D Reconstruction of a Neuron from an Anestrous Animal at a Side View (Tilted at $90^{\circ}$ angle) 


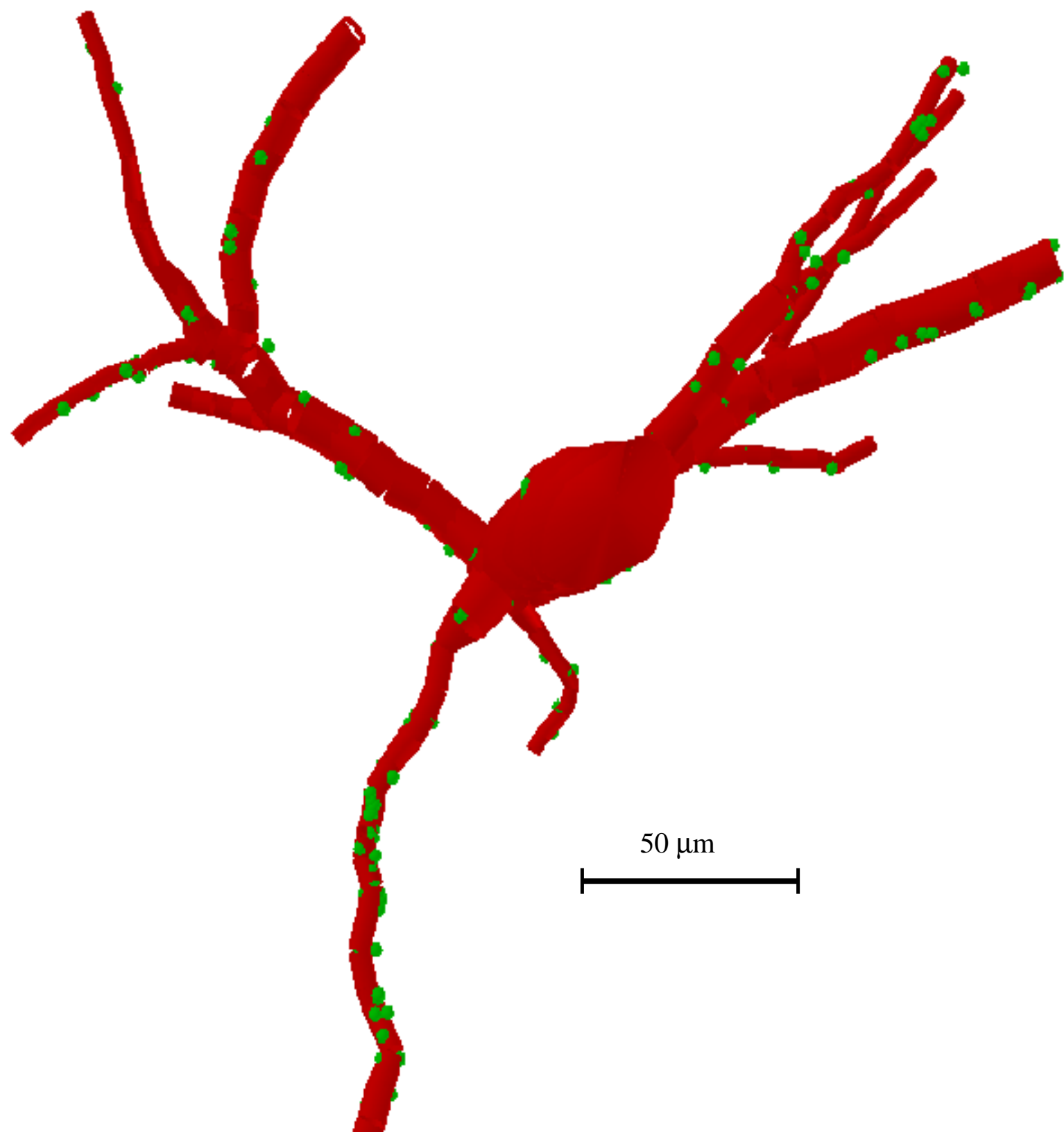

Figure 30. Neurolucida 3-D Reconstruction of a Neuron from an Anestrous Animal at a Top View (Tilted at $180^{\circ}$ angle) 


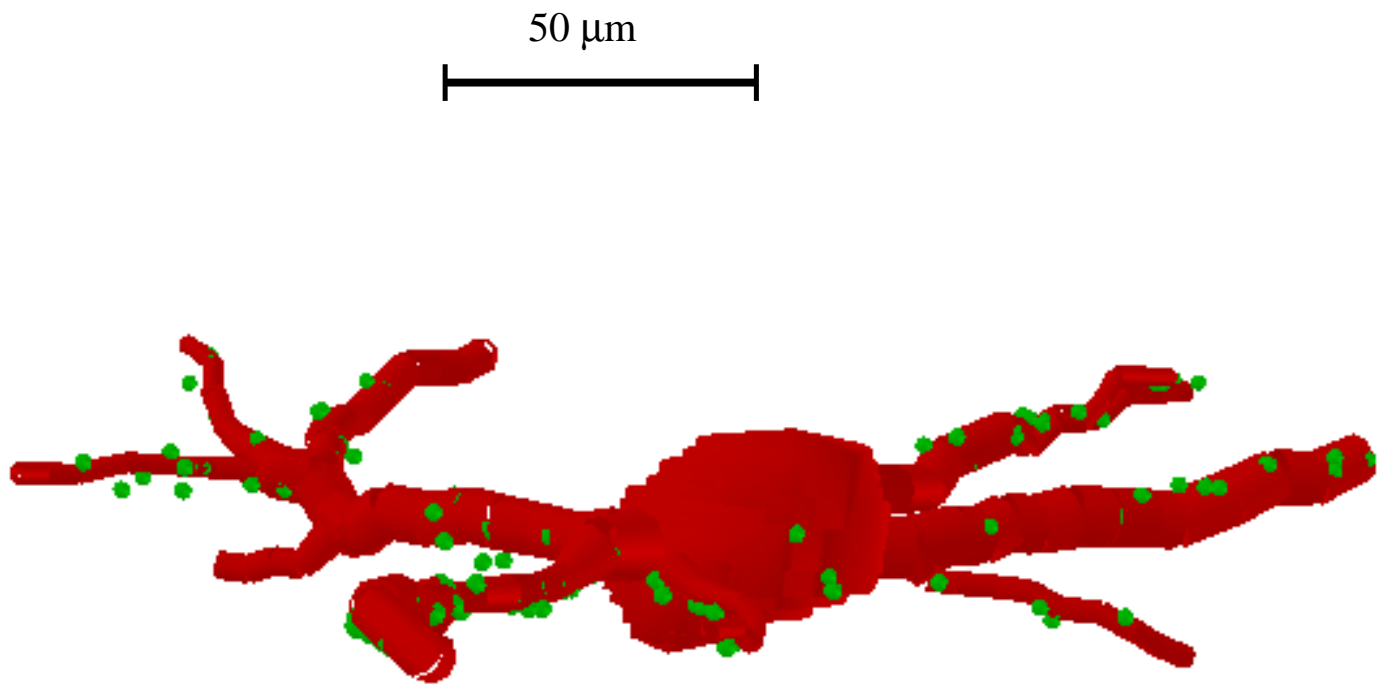

Figure 31. Neurolucida 3-D Reconstruction of a Neuron from an Anestrous Animal at a Side View (Tilted at $270^{\circ}$ angle) 


\section{CHAPTER FIVE: DISCUSSION}

The decrease in LH output during the anestrous season is brought about by an increase in sensitivity to estrogen negative feedback. Estradiol decreases frequency of LH pulses during the anestrous season due to the actions of the A15 dopaminergic neural group. One possible mechanism (a change in input on A15 neurons during the breeding season to non-breading season transition) by which changes in activity if this neural group might occur was examined by analyzing the synaptic contacts and neural morphology of these neurons during the breeding season and non-breeding season.

The studies in this work show that there likely is a change in synaptic contacts on the A15 neurons along with a change in neural morphology between the breeding season to non-breeding season transition. The total number of synpasin-positive contacts increases between the breeding season and the non-breeding season. However, this increase appeared to occur on dendrites not on the soma.

Likewise, there is not a change in density of contacts on either the dendrite or cell body with the density of contacts being a measure of the number of contacts per unit area $\left(\mu \mathrm{m}^{2}\right)$. This suggests that there must be an increase in size of the dendrites in order to accommodate an increase in contact number without a change in density. This is found to occur; the mean lengths of the dendrites in anestrous animals are longer than the mean length of dendrites in the breeding season animals. Concurrent with the increase in length, there is also an increase in mean surface area of the dendrites, and an increase in the average number of bifurcations between the breeding season and non-breeding season ewes. However, no changes in neural morphology of the soma occur which is in accord with the contact data above. 
The method used in these studies to examine neural contacts onto A15 neurons was a procedure where synapsin I protein was labeled and counted when found in close apposition to tyrosine hydroxylase-positive neurons. Synapsin I is an actin-binding protein that is found exclusively in pre-synaptic vesicles. It is a phosphoprotein that is thought to regulate the availability of vesicles for neurotransmitter release (Mandell, Czernik, De Camilli, Greengard, Townes-Anderson 1992). This is a somewhat different approach to analyzing contacts on neurons than the typical approach, which is to use electron microscopy studies. An electron microscopic study possibly would give a more precise indication of whether a bouton is actually in contact with a neuron soma or dendrite. In an electron microscopy study done on sheep GnRH neurons, there was found a change in contacts was found on both the somata and the dendrites when comparing breeding season and anestrous animals (Xiong, Karsch, and Lehmna 1997). This was not the case in the A15 dopaminergic neurons studied here at the light microscopic level, where only a difference was found on the dendrites and not on the somata. However, the seasonal differences in GnRH neuronal input have recently been demonstrated using synapsin I staining and confocal analysis (Jansen HT, personal communication). Moreover, in the developing suprachiasmatic nucleus of the rat, synapsin I immunohistochemistry was found to be a reliable marker of synapse formation. The positive identification of synapsin I immunoreactivity correlated very precisely with the development of synapses in the SCN as seen in ultrastructural analysis (Moore and Bernstein 1989). Therefore staining for synapsin is probably a useful method for determining changes in synaptic contact. 
Another issue of concern is the penetration of the synapsin antibody into the tissue sections during staining. It was observed during the analysis of sections that the amount of synapsin staining appeared to be the densest at the top and bottom of the section with a progressive decrease moving towards the middle. This raises the possibility that the changes in contacts observed could have been a result of an artifact. An additional possibility is that no change in contacts on the soma was observed because a lack of antibody binding decreased the sensitivity of the analysis. However, as the staining procedure used was identical for every section, antibody penetration should be similar in every tissue section, this problem unlikely to account for the observed differences. Because of this limitation, the staining may not necessarily give a complete count of contacts, but should still provide a good estimation of change in contacts.

The changes in morphology observed were found by staining tissue using an antibody against the tyrosine hydroxylase $(\mathrm{TH})$ enzyme and using the Neurolucida program to analyze the stained neurons. This raises the question of whether the increase in length, surface area, and bifurcations during anestrus is caused by an actual change in neural morphology or by an increase in the amount of TH enzyme resulting in increased staining. Beccavin, Malpaux, and Tillet (1998) provide a possible answer to this when they found that there is an increase in TH mRNA during the breeding season compared to the non-breeding season. This indicates that the increase in dendritic arbors found during anestrus is probably not caused by an increase in synthesis of TH enzyme because TH mRNA levels are highest during the breeding season when dendrite length, number of bifurcations, and surface area are the lowest. Also there are more TH-positive neurons in the A15 during the breeding season than during the non-breeding season (Lehman et al. 
1996). This data indicates that there may be an overall increase in the amount of $\mathrm{TH}$ proteins in A15 neurons during the breeding season compared to the non-breeding season.

Another explanation for the observed change in dendrite length could be that the orientation of the dendrites are changing, and because of this the dendrites were cut close to the soma when the tissue slices were made. To address this issue, the confocal stacks were examined to see if there was a difference in dendrites ending in the top or bottom of the stack during the breeding season or non-breeding season (figure 12,13). This would indicate that the dendrites are being cut by the microtome and the orientation is changing, and not that there is a decrease in length of the dendrites. However, it was found that this was not the case. The results indicate that the number of endings at the top and bottom of the stack are not statistically different between the breeding season and non-breeding season, thus, there probably is a decrease in dendrite mean length and not a change in orientation.

In the robustus archistriatalis, a nucleus that is involved in singing in the canary, a difference in neuronal morphology is observed between neurons in the nucleus based on location (DeVoogd and Nottebohm 1981). Neurons at the margin of the nucleus have more spines than neurons found elsewhere. However, these may represent two different neuronal phenotypes, and only dopaminergic A15 neurons were examined in the present studies. The neurons that were selected to be analyzed in this study were chosen based on whether the cell bodies were complete or not. The selection was random, and in the first experiment there should not have been any bias based on neuron location. 
The change in contacts on the A15 neurons may represent a change in activity of the neurons. Previous studies have provided anatomical and functional evidence of innervation from the vmPOA to the A15 (Jansen et al. 1997; Jansen et al. 1999; and Anderson et al. 2001). Neurons in the vmPOA that project to the A15 have estrogen receptors (Jansen et al. 1999). Also when estradiol is implanted in this area during the anestrous season in ovariectomized ewes a drop in LH pulse frequency is seen, which is reversed by a dopamine receptor antagonist (Anderson et al. 2001). These results are consistent with the hypothesis that the vmPOA neurons are contacting the A15 neurons and activating them.

In previous work it was also shown that A15 neurons are inhibitory (Havern, Whisnant, and Goodman 1994; Lehman et al. 1996; Goodman et al. 2000) to LH pulse frequency and stimulated by estradiol in anestrus. A hypothesis could then be formed that, during anestrus, estrogen is acting on neurons in the vmPOA, which are stimulating dopaminergic neurons in the A15, and these A15 neurons are then inhibiting GnRH neurons decreasing the release of LH. During the breeding season the connection between the vmPOA and the A15 neurons is severed preventing any inhibitory actions of estrogen. Based on the results of experiment 1 it could be speculated that some system during the transition into anestrus causes the dendrites to increase in size and recieve axodendritic synapses from other neurons (possibly from the vmPOA), resulting in activation of the A15 and inhibition of GnRH. However, this is fairly speculative because it is impossible from this study to tell whether the synaptic connections formed are inhibitory or stimulatory, and it is impossible to tell the origin of neurons making synaptic contact with the A15 neurons. 
The role of thyroid hormone was examined in experiment 2 . It has been established that thyroid hormone is necessary for the transition from the breeding season into anestrus (Nichols et al. 1988a; Nichols, Follett, Golsmith and Pearson 1988b; Follett and Potts 1990). Therefore A15 neurons were studied to determine whether thyroid hormones were necessary for the seasonal effects on neural contacts and morphology. The results indicate no change in total contacts in thyroidectomized, $\mathrm{T}_{4}$ treated, or intact animals. There was also no change in density of contacts. However, there were two changes in neural morphology. Thyroid intact and $\mathrm{T}_{4}$ treated animals had an increase in mean length of dendrites compared to thyroidectomized animals. The second was an increase in surface area seen in T4 treated animals compared to the intact and thyroidectomized animals. It seems counterintuitive that the number of total contacts does not change when density stays the same over a greater length, but when looking at the results, the mean value for the number of contacts is greater in the intact and T4 treated animals compared to the thyroidectomized animals. However, these changes were not statistacly significant.

In this study most of the neurons used for analysis were selected from the caudal portion of the A15 nucleus. This was not intentional and was a result of a limited pool of tissue sections that were further caudal in the hypothalamus than normally selected for study of A15 neurons. This may explain some of the discrepancies seen in this experiment compared to experiment 1 such as no decrease in contacts seen in thyroidectomized ewes, which should be equivalent to a breeding season ewe.

Another possible explanation for a lack of effect of $T_{4}$ is that $T_{4}$ replacement in this experiment was given via cannulas in the lateral ventricle. This may have impacted 
the results of the T4 replacement group, because only a limited portion of the brain would have been exposed to this hormone. Results of animals receiving thyroid replacement peripherally may have differed from those receiving thyroid replacement centrally.

The last thing to consider is that all animals used in this experiment were sacrificed during the anestrus season (June). This may have an impact when comparing results from the thyroidectomized animals to thyroid intact animals in the breeding season (used in experiment 1). Since the thyroidectomized animals do not show a change in contacts, and the thyroid intact breeding season animals used in experiment 1 had a decrease in contacts on dendrites (figure 19).

Thyroid hormone is involved in neural morphology of the developing central nervous system (Slotkin and Slepetis 1984), and thyroid hormone has been found to influence neurochemical organization of the adult rat brain (Calza, Aloe, and Giardino 1997). The results of experiment 2 indicate changes in neural morphology that are dependent on thyroid hormone. Thyroid hormone may then be involved in the system that increases dendritic length and axodendritic contacts on A15 neurons during the breeding season to non-breeding season transition.

The most work in neural plasticity in the ewe has been done on GnRH neurons. In $\mathrm{GnRH}$ neurons in the preoptic area examined at the EM level there are more contacts on both dendrites and soma during the breeding season than during the non-breeding season (Xiong et al. 1997), which is opposite the results found in the A15 in this study. The results of Xiong et al. were seen in ovariectomized animals receiving constant release estradiol implants indicating that it is not an effect caused by changing levels of estradiol treatment. This was true for the studies done in this work as well. The animals 
used in these experiments were ovariectomized ewes receiving implants that released estradiol at a constant level. This contrasts with the songbird where changes in neural morphology have been associated with changes in gonadal hormones. Testosterone given to female birds can cause an increase in dendrite length, an increase in the size of the RA nucleus, increases in synaptic contacts on neurons in the RA, and an increase in synaptic vesicles in those synapses (DeVoogd and Nottebohm 1981; DeVoogd, Nixdorf, and Nottebohm 1984).

Changes in neuronal morphology have also been seen in preoptic GnRH neurons in the ewe that resemble the changes in A15 neuron morphology found in these studies (Lehman et al. 1986). At the light microscopic level GnRH neurons have fewer and shorter dendrites during the breeding season than during anestrous. The somas of GnRH neurons do not appear to change in breeding season or non-breeding season animals (Xiong et al. 1997). Changes in neural morphology of songbird neurons also can occur with season when given a constant level of testosterone (Hill and DeVoogd 1991). Birds exposed to short day lighting have smaller dendritic fields and fewer spines than birds exposed to long day lighting. This demonstrates that season and photoperiod can have an effect on neurons in another species similar to those found in this work in sheep.

The role of thyroid hormone in changing neural morphology of A15 neurons found in experiment 2 adds additional possibilities to the changes in the action of A15 neurons. A hypothesis could be formed that thyroid hormone is part of a system that allows an increase in dendritic length during anestrus. This increased dendrite length allows stimulatory axodendritic contacts to form on A15 neurons (possibly from the vmPOA). The stimulated A15 neurons then inhibit GnRH neurons decreasing the output 
of LH maintaining the low level of LH characteristic of the non-breeding season. Late in anestrus a system involving thyroid hormone induces the transition back to the breeding season. Thyroid hormone may allow a decrease in the length of A15 neuron dendrites breaking the stimulatory axodendritic connections formed during anestrus. The A15 neurons are no longer stimulated, and this releases the inhibition of GnRH neurons allowing the return of breeding season levels of $\mathrm{GnRH}$ and $\mathrm{LH}$.

Possible future directions for research include the following. Studying the A15 neurons at the EM level to confirm an increase in contacts during anestrus. Do another study looking at morphology of A15 neurons at the light microscope level using Golgi stain. Stain neurons in hypothalamus with Golgi staining during anestrus. Find the general region of the A15 using anatomical landmarks locating neurons that are active with fos labeling. Examine only the Golgi stained neurons that are also labeled with fos in the A15 area using Neurolucida to elucidate their structure. Then repeat with breeding season animals examining Golgi stained neurons in the general A15 area. This addresses the issue of whether the change in morphology is due to a change in TH level. Also using fos labeled cells allows morphology to be analyzed in cells that are active during anestrus. Studies to determine what types of synapses are being formed on the A15 neurons would also be worth doing.

In summary, during the non-breeding season estrogen inhibits LH pulse frequency preventing the preovulatory estradiol rise and thus inhibiting ovulation. This increased estrogen sensitivity during the non-breeding season is mediated through the A15 dopaminergic neurons, which do not contain estrogen receptors. Estrogen acts on the neurons in the vmPOA that may then act on the A15 neurons. These experiments tested 
whether there is a change in contacts and neuronal morphology during the breeding season to non-breeding season transition. There was an increase in contacts on dendrites during the non-breeding season and increases in dendrite mean length, mean surface area, and mean number of bifurcations. It could be hypothesized that this increase in dendrite length that causes an increase in contacts results in an increase innervation of the A15 from the vmPOA, which activates the A15. This then induces the inhibition of GnRH neurons in the ME. Thyroid hormone is essential to the reproductive transition from the non-breeding season to the breeding season. Therefore, thyroid hormone was examined in experiment 2 to determine if it played a role in the plastic changes seen in experiment 1. There was an increase in mean dendrite length in thyroid intact and $T_{4}$ treated animals compared to the thyroidectomized animals. There was also an increase in mean surface area of the dendrites in the $T_{4}$ treated group compared to the thyroid intact and thyroidectomized groups. The hypothesis then becomes that thyroid hormones allow or modulate the alteration in A15 neurons that result in the increase in contacts. 


\section{LITURATURE CITED}

Anderson GM, Connors JM, Hardy SL, Miroslav V, Goodman RL. 2001. Oestradiol microimplants in the ventromedial preoptic area inhibit secretion of luteinizing hormone via dopaminergic neurons in anoestrous ewes. Unplublished.

Beccavin C, Malpaux B, Tillet Y. 1998. Effect of oestradiol and photoperiod on TH mRNA concentrations in A15 and A12 dopamine cell groups in the ewe. Journal of Neuroendocrinology. 10:59-66.

Bertrand F, Thiery J-C, Picard S, Malpaux B. 1999. Implication of D2-like dopaminergic receptors in the median eminence during the establishment of long-day inhibtion of LH secretion in the ewe. Journal of Endocrinology 163: 243-254.

Bittman EL, Dempsey RJ, Karsch FJ. 1983. Pineal melatonin secretion drives the reproductive response to daylength in the ewe. Endocrinology. 113: 2276-2283.

Bittman EL, Karsch FJ, Hopkins JW. 1983. Role of the pineal gland in ovine photoperiodism: regulation of seasonal breeding and negative feedback effects of estradiol upon luteinizing hormone secretion. Endocrinology. 113: 329-336.

Bittman EL, Weaver DR. 1990. The distribution of melatonin binding sites in neuroendocrine tissues of the ewe. Bio of Rep. 43: 986-993.

Boukhliq R, Goodman RL, Berriman SJ, Adrian B, Lehman MN. 1999. A subset of gonadotropin-releasing hormone neurons in the ovine medial basal hypothalamus is activated during increased pulsatile luteinizing hormone secretion. Endocrinology. 140: 5929-5935.

Bronson FH. 1989. Mammals: strategies and perspectives In Mammalian Reproductive Biology. pg. 1-7.

Calza L, Aloe L, Giardino L. 1997. Thyroid hormone-induced plasticity in the adult rat brain. Brain Research Bulletin. 44: 549-557.

Clarke IJ, Cummins JT. 1982. The temporal relationship between gonadotropin releasing hormone $(\mathrm{GnRH})$ and luteinizing hormone $(\mathrm{LH})$ secretion in ovariectomized ewes. Endocrinology. 111: 1737-9.

Clarke IJ, Lincoln GA. 1994. Photoperiodically-induced cycles in the secretion of prolactin in hypothalamo-pituitary disconnected rams: evidence for translation of the melatonin signal in the pituitary gland. Journal of Neuroendocrinology. 6: 251-260.

Clarke IJ. 1987. Control of GnRH secretion. J. Reprod. Fert. 34:1-8 
Clower RP, Nixdorf BE, DeVoogd TJ. 1989. Synaptic plasticity in the hypoglossal nucleus of female canaries: structural correlates of season, hemisphere, and testosterone treatment. Behavioral and Neural Biology. 52: 63-77.

Dahl GE, Evans NP, Suzanne MM, Karsch FJ. 1994. The thyroid gland is required for reproductice neuroendocrine responses to photoperiod in the ewe. Endocrinology. 135:10-15.

Dahl GE, Evans NP, Thrun LA, Karsch FJ. 1995. Thyroxine is permissive to seasonal transitions in reproductive neuroendocrine activity in the ewe. Biology of Reproduction. 52: 690-696.

DeVoogd T, Nottebohm F. 1981. Gonadal hormones induce dendritic growth in the adult avian brain. Science. 214: 202-204.

DeVoogd TJ, Nixdorf B, Nottebohm F. 1985. Synaptogenesis and changes in synaptic morphology related to acquisition of a new behavior. Brain Research. 329: 304-308.

DeVoogd TJ, Nottebohm F. 1981. Sex differences in dendritic morphology of a song control nucleus in the canary: a quantitative golgi study. The Journal of Comparative Neurology. 196: 309-316.

Ferin M, VanVugt D, Wardlow S. 1984. The hypothalamic control of the menstrual cycle and the role of endogenous opioid peptides. Recent Prog Horm Res. 40: 441-85

Fernandez-Galaz MC, Morschl E, Chowen JA, Torres-Aleman I, Naftolin F, GarciaSegura LM. 1997. Role of astroglia and insulin-like growth factor-I in gonadal hormonedependent synaptic plasticity. Brain Research Bulletin. 44:525-531.

Follett BK, Potts C. 1990. Hypothyroidism affects reproductive refractoriness and the seasonal oestrous period inWelsh Mountain ewes. Journal of Endocrinology. 127: 103109.

Gayrard V., Malpaux B, Tillet Y, Thiery JC. 1994. Estradiol increases tyrosine hydroxylase activity of the A15 nucleus dopaminergic neurons during long days in the ewe. Bio of Rep. 50: 1168-1174.

Gilad GM, Reis DJ. 1979. Collateral sprouting in central mesolimbic dopamine neurons; biochemical and immunocytochemical evidence of changes in the activity and distribution of tyrosine hydroxylase in terminal fields and in cell bodies of A10 neurons. Brain Research. 160:17-36.

Goodman RL, Karsch FJ. 1980. Pulsatile secretion of luteinizing hormone; differential suppression by ovarion steroids. Endocrinology. 107: 1286-90. 
Goodman RL, Knobil E. 1981. The sites of ovarian steroids in the regulation of LH secretion. Neuroendocrinology. 32: 57-63.

Goodman RL, Meyer SL. 1984. Effects of pentobarbital anesthesia on tonic luteinizing hormone secretion in the ewe: evidence for active inhibition of luteinizing hormone in anestrus. Bio of Rep. 30: 374-381.

Goodman RL, Robinson JE, Kendrick KM, Dyer RG. 1995. Is the inhibitory action of estradiol on luteinizing hormone pulse frequency in anestrous ewes mediated by noradrenergic neurons in the preoptic area? Neuroendocrinology. 61: 284-92.

Goodman RL, Thiery J-C, Delaleu B, Malpaux B. 2000. Estradiol increases multiunit electrical activity in the A15 area of ewes exposed to inhibitory photoperiods. Bio of Rep. 63: 1352-1357.

Goodman RL. 1999. Seaonal Reproduction, Mammals In Enyclopedia of Reproduction. 4:341-351.

Gottesfeld Z, Garcia CJ, Chronister RB. 1987. Perinatal, not adult, hypothyroidism suppresses dopaminergic axon sprouting in the deafferented olfactory tubercle of adult rat. Journal of Neuroscience Research. 18: 568-573.

Havern RL, Whisnant CS, Goodman RL. 1994. Dopaminergic structures in the ovine hypothalamus mediating estradiol negative feedback in anestrous ewes. Endocrinology. 134: 1905-13.

Havern RL, Whisnant CS, Goodman RL. 1991. Hypothalamic sites of catecholamine inhibtion of luteinizing hormone in the anestrous ewe. Bio of Rep. 44: 476-482.

Herbison AE, Robinson JE, Skinner DC. 1993. Distribution of Estrogen Receptorimmunoreactive cells in the preoptic area of the ewe: Co-localization with glutamic acid decarboxylase but not luteinizing horomone-releasing hormone. Neuroendocrinology. 57: 751-759.

Hill KM, DeVoogd TJ. 1991. Altered daylength affects dendritic structure in a song related brain region in red-winged blackbirds. Behavioral and neural biology. 56: 240250 .

Jansen HT, Auyung E, Stefanovic I, Lehman MN, Goodman RL. 1997. The neural afferents and efferents of the hypothalamic A15 region in the ewe: combined anterograde and retrograde tract-tracing. Annual Meeting of the Society for Neuroscience.

Jansen HT, Cutter CT, Anderson GM, Hardy SL, Lehman MN, Goodman RL. 1999. Restricted distribution of estrogen receptor- $\alpha$ containing afferents to the hypothalamic A15 region in the ewe. Annual Meeting of the Society for Neuroscience. 
Karsch FJ, Bittman EL, Foster DL, Goodman RL, Legan SJ, Robinson JE. 1984. Neuroendocrine basis of seasonal reproduction. Recent Prog Horm Res. 40: 185-252.

Karsch FJ, Dahl GE, Hachigan TM, Thrun LA. 1995. Involvement of thyroid hormones in seasonal reproduction. Journal of Reproduction and Fertility Supplement. 49: 409422.

Karsch FJ, Foster DL, Bittman EL, Goodman RL. 1983. A role for estradiol in enhancing luteinizing hormone pulse frequency during the follicular phase of the estrous cycle of sheep. Endocrinology. 113: 1333-9

Karsch FJ, Goodman RL, Legan SJ. 1980. Feedback basis of seasonal breeding: test of an hypothesis. J. Reprod. Fert. 58: 521-535.

Karsch FJ, Robinson JE, Woodfill CJ, Brown MB. 1989. Circannual cycles of luteinizing hormone and prolactin secretion in ewes during prolonged exposure to a fixed photoperiod: evidence for an endogenous reproductive rhythm. Bio of Rep. 41: 10341046.

Kim S-J, Foster DL, Wood RI. 1999. Prenatal testosterone masculinizes synaptic input to gonadotropin-releasing hormone neurons in sheep. Bio of Rep. 61: 599-605.

Kokoris GJ, Lam NY, Michel F, Silverman A, Gibson MJ. 1988. Translated gonadotropin-releasing hormone neurons promote pulsatile luteinizing hormone secretion in congenitally hypogonadal (hpg) male mice. Neuroendocrinology. 48: 45-52.

Krsmanovic LZ, Stanko SS, Merelli F, Dufour SM, Virmani MA, Catt KJ. 1992. Calcium signaling and episodic secretion of gonadotropin-releasing hormone in hypothalamic neurons. Proc. Natl. Acad. Sci. 89: 8462-66.

Legan SJ, Karsch FJ, Foster DL. 1977. The endocrine control of seasonal reproductive function in the ewe: marked change in response to the negative feedback action of estradiol in luteinizing hormone secretion. Endocrinology. 101: 818-824.

Legan SJ, Karsch FJ. 1979. Neuroendocrine regulation of the estrous cycle and seasonal breeding in the ewe. Biol Reprod. 20: 74-85.

Lehman MN, Durham DM, Jansen HT, Adrian B, Goodman RL. 1996. Dopaminergic A14/A15 neurons are activated during estradiol negative feedback in anestrous, but not breeding season, ewes. Endocrinology. 137: 4443-50.

Lehman MN, Goodman RL, Karsch FJ, Jackson GL, Berriman SJ, Jansen HT. The GnRH system of seasonal breeders: anatomy and plasticity. Brain Research Bulletin. 44: 445-457. 
Lehman MN, Karsch FJ. 1993. Do gonadotropin-releasing hormone, tyrosine hydroyxylase-, and $\beta$-endorphin-immunoreactive neurons contain estrogen receptors? A double-label immunocytochemical study in the Suffolk ewe. Endocrinology. 133: 887895.

Lehman MN, Robinson JE, Karsch FJ, Silverman AJ. 1986. Immunocytochemical localization of luteinizing hormone-releasing hormone (LHRH) pathways in the sheep brain during anestrus and the mid-luteal phase of the estrous cycle. J Comp Neurol. 244: 14-35.

Levine JE, Pau KY, Ramirez VD, Jackson GL. 1982. Simultaneous measurement of luteinizing hormone-releasing hormone and luteinizing hormone release in unanesthetized, ovariectomized sheep. Endocrinology. 111: 1449-55.

Lincoln GA, Maeda KI. 1992. Reproductive effects of placing micro-implants of melatonin in the mediobasal hypothalamus and preoptic area in rams. Journal of Endo. 132: 201-215.

Lincoln GA, Short RV. 1980. Seasonal breeding: nature's contraceptive. Recent Prog Horm Res. 36: 1-52.

Malpaux B, Daveau A, Maurice F, Gayrard V, Thiery J. 1993. Short-day effects of melatonin on luteinizing hormone secretion in the ewe: evidence for central sites of action in the mediobasal hypothalamus. Bio of Rep. 48: 752-760.

Malpaux B, Daveau A, Maurice F, Locatelli A, Thiery J-C. 1994. Evidence that melatonin bininding sites in the pars tuberalis do not mediate the photoperiodic actions of melatonin on LH and prolactin secretion in the ewes. Journal of Reproduction and Fertility. 101: 625-632.

Malpaux B, Deveau A, Maurice-Mandon F, Duarte G, Chemineau P. 1998. Evidence that melatonin acts in the premammillary hypothalamic area to control reproduction in the ewe: presence of binding sites and stimulation of luteinizing horomone secretion by in situ microimplant delivery. Endocrinology. 139: 1508-1516.

Malpaux B, Robinson JE, Wayne NL, and Karsch FJ. 1989. Regulation of the onset of the breeding season of the ewe: importance of long days and of an endogenous reproductive rhythm. Journal of Endocrinology. 122: 269-278.

Malpaux B, Skinner DC, Maurice F. 1995. The ovine pars tuberalis does not appear to be targeted by melatonin to modulate luteinizing hormone secretion, but may be important for prolactin release. Journal of Neuroendocrinology. 7: 199-206.

Malpaux B, Viguie C, Skinner DC, Thiery JC, Pelletier J, Chemineaau P. 1996. Seasonal breeding in sheep: mechanism of action of melatonin. Animal Reproduction Science. 42: 109-117. 
Malpaux B, Wayne NL, Karsch FJ. 1988. Termination of the breeding season in the Suffolk ewe: involvement of an endogenous rhythm of reproduction. Bio of Rep. 39: 254-263

Mandell JW, Czernik AJ, DeCamilli P, Greegard P, Townes-Anderson E. 1992. Differential expression of synapsin I and II among rat retinal synapses. Journal Neuroscience. 12: 1736-49.

Marler P, Waser MS. 1977. Role of auditory feedback in canary song development. J Comp Physiol Psychol. 91: 8-16.

Meyer SL, Goodman RL. 1985. Neurotransmitters involved in mediating the steroiddependent suppression of pulsatile luteinizing hormone secretion in anestrous ewes: effects of receptor antagonists. Endocrinology. 116: 2054-2061.

Moenter SM, Caraty A, Locatelli A, Karsch FJ. 1991. Pattern of gonatropin-releasing hormone $(\mathrm{GnRH})$ secretion leading up to ovulation in the ewe: existence of a preovulatory GnRH surge. Endocrinology 192: 1375-1384.

Moeneter SM, Woodfill CJ, Karsch FJ. 1991. Role of the thyroid gland in seasonal reproduction: thyroidectomy blocks seasonal suppression of reproduction neuroendocrine activity in ewes. Endocrinology. 128: 1337-44.

Moore RY, Bernstein ME. 1989. Synaptogenesis in the rat suprachiasmatic nucleus demonstrated by electron microscopy and synapsin I immunorectivity. Journal Neuroscience. 9: 2151-62.

Naftolin F, Leranth C, Perez J, Garcia-Segura LM. 1993. Estrogen induces synaptic plasticity in adult primate neurons. Neuroendocrinology. 57: 935-939.

Nicholls TJ, Follett BK, Goldsmith AR, Pearson H. 1988b. Possible homologies between photorefractoriness in sheep and birds: the effect of thyroidectomy on the length of the ewe's breeding seaon. Reproduction, Nutrition, Development. 28: 375-385.

Olmos G, Naftolin F, Perez J, Tranque PA. 1989. Synaptic remodeling in the rat arcuate nucleus during the estrous cycle. Neuroscience. 32: 663-667.

Parkinson TJ, Follet BK. 1994. Effect of thyroidectomy upon seasonality in rams. Journal of Reproduction and Fertility. 101: 51-58.

Plant TM, Perera AD. 1997. Ultrastructural studies of neuronal correlates of the pubertal reaugmentation of hypothalamis gonadotropin-releasing hormone $(\mathrm{GnRH})$ release in the Rhesus Monkey. The Journal of Comparative Neurology. 385: 71-82. 
Pau KJ, Jackson GL. 1985. Effect of frontal hypothalamic deafferentation on photoperiodic induced changes of luteinizing hormone secretion in the ewe. Neuroendocrinology. 41: 72-8.

Reviers MM, Ravault J, Tillet Y, Pelletier J. 1989. Melatonin binding sites in the sheep pars tuberalis. Neuroscience Letters. 100: 89-93.

Robinson JE, Karsch FJ. 1987. Photoperiodic history and a changing melatonin pattern can determine the neuroendocrine response of the ewe to day length. J Reprod Fertil. 80: $159-65$.

Robinson JE, Wayne NL, Karsch FJ. 1985. Refractoriness to inhibitory day length initiates the breeding season of the Suffolk ewe. Bio of Rep. 32: 1024-1030.

Skinner DC, Malpaux B, Delaleu B, Caraty A. 1995. Luteinizing hormone (LH)-r eleasing hormone in third ventricular cerebrospinal fluid of the ewe: correlation with $\mathrm{LH}$ pulses and the LH surge. Endocrinology. 136: 3230-37.

Slotkin TA, Slepetis RJ. 1984. Obligatory role of thyroid hormones in development of peripheral sympathetic and central nervous system catecholaminergic neurons: effects of propylthiouracil-induced hypothyroidism on transmitter levels, turnover, and release. J Pharmacol Exp Ther. 230: 53-61.

Smith GT, Brenowitz EA, Wingfield JC. 1997. Roles of photoperiod and testosterone in seasonal plasticity of the avian song control system. J Neurobiol. 32: 426-442.

Stefanovic I, Adrian B, Jansen HT, Lehman MN, Goodman RL. 2000. The ability of estradiol to induce fos expression in a subset of estrogen receptor- $\alpha$-containing neurons in the preoptic area of the ewe depends on reproductive status. Endocrinology. 141: 190-196.

Terasawa EI, Keen KL, Mogi K, Claude P. 1999. Pulsatile release of luteinizing hormone releasing hormone (LHRH) in cultured LHRH neurons derived from the embryonic olfactory placode of the Rhesus Monkey. Endocrinology. 140: 1432-41.

Thiery JC, Gayrard V, Le Corre S, Viguie C, Martin GB, Cheminaeu P, Malpaux B. 1995. Dopaminergic control of LH secretion by the A15 nucleus in anestrous ewes. J. Reprod. Fertil., Suppl., 49:285-296.

Thiery JC, Martin GB, Tillet Y, Caldani M, Quentin M, Jamain C, Ravault JP. 1989. Role of hypothalamic catecholamines in the regulation of luteinizing hormone and prolactin secretion in the ewe during seasonal anestrus. Neuroendocrinology. 49: 80-87.

Thrun LA, Dahl GE, Evans NP, Karsch FJ. 1993. Involvement of thyroid hormone in the transition to anestrus in the ewe: Is there a 'window' of time that thyroid hormone act 
on the reproductive neuroendocrine axis? Journal of Reproduction and Fertility Abstract Series 11 Abstract 11

Tillet Y, Batailler M, Krieger-Poullet M, Thibault J. 1990. Presence of dopamineimmunoreactive cell bodies in the catecholaminergic A15 of the sheep brain. Histochemistry. 93: 327-333.

Tillet Y, Thibault J. 1993. Morphological relationships between tyrosine hydroxylaseimmunoreactive neurons and dopamine- $\beta$-hydroxylase-immunoreactive fibres in dopamine cell group A15 of the sheep. Journal of Chemical Neuroanatomy. 6:69-78.

Tillet Y, Thibault J. 1989. Catecholamine-containing neurons in the sheep brainstem and ciencephalon: immunohistochemical study with tyrosine hydroxylase (TH) and dopamine beta-hydroxylase (DBH) antibodies. J Comp Neurol. 290: 69-104.

Tortonese DJ, Lincoln GA. 1994. Photoperiodic modulation of the dopaminergic control of pulsatile LH secretion in sheep. Journal of Endocrinology. 143: 25-32.

Tortonese DJ, Lincoln GA. 1995. Effects of melatonin in the mediobasal hypothalamus on the secretion of gonadotrophins in sheep: role of dopaminergic pathways. Journal of Endocrinology. 146: 543-552.

Viguie C, Battaglia DF, Krasa HB, Thrun LA, Karsch FJ. 1999. Thyroid hormones act primarily within the brain to promote the seasonal inhibtion of luteinizing hormone secretion in the ewe. Endocrinology. 140: 1111-1117.

Viguie C, Caraty A, Locatelli A, and Malpaux B. 1995. Regulation of LHRH secretion by melatonin in the ewe. I. Simultaneous delayed increase in LHRH and LH pulsatile secretion. Biol. Reprod. 52: 1114-1120.

Viguie C, Jansen HT, Glass JD, Watanabe M, Billings HJ, Coolen L, Lehman MN, and Karsch FJ. 2001. Potential for polysialylated form of neural cell adhesion moleculemediated neuroplasticity within the gonadotropin-releasing hormone neurosecretory system of the ewe. Endocrinology. 142: 1317-1324.

Wayne NL, Malpaux B, Karsch FJ. 1990. Photoperiodic requirements for timing onset and duration of the breeding season in the ewe. Journal of Comparative Physiology. 166:835-842.

Wayne NL, Malpaux B, Karsch FJ. 1988. How does melatonin code for day length in the ewe: duration of nocturnal melatonin release or coincidence of melatonin with a lightentrained sensitive period. Bio of Rep. 39:66-75.

Wayne NL, Malpaux B, Karsch FJ. 1990. Photoperiodic requirements for timing onset and duration of the breeding season of the ewe: synchronization of an endogenous rhythm of reproduction. J Comp Physiol. 166: 835-842. 
Webster JR, Moenter SM, Barrell GK, Lehman MN, and Karsch FJ. 1991. Role of the thyroid gland in seasonal reproduction: III. Thyroidectomy blocks seasonal suppression of GnRH secretion in sheep. Endocrinology. 129. 1635-1643.

Whisnant CS, Goodman RL. 1994. Effect of anterior hypothalamic deafferentation on the negative feedback of gonadal steroids on luteinizing hormone pulse frequency in the ewe. Domestic Animal Endocrinology. 11:151-159.

Whisnant CS, Havern RL, Goodman RL. 1991. Endogenous opioid suppression of luteinizing hormone pulse frequency and amplitude in the ewe: hypothalamic sites of action. Neuroendocrinology. 54: 587-593.

Witkin JW, Ferin M, Popilskis SJ, Silverman AN. 1991. Effects of gonadal steroids on the ultrastructure of GnRH neurons in the Rhesus Monkey: synaptic input and glial apposition. Endocrinology. 129: 1083-1092.

Woodfill C, Wayne NL, Moenter SM, Karsch FJ. 1994. Photoperiodic synchronization of a circannual reproductive rhythm in sheep: identification of season-specific time cues. Bio of Rep. 50: 965-976.

Woodfill CJ, Robinson JE, Malpaux B, Karsch FJ. 1991. Synchronization of the circannual reproductive rhythm of the ewe by discrete photoperiodic signals. Bio of Rep. 45: 110-121.

Xiong J-J, Karsch FJ, Lehman MN. 1997. Evidence for seasonal plasticity in the gonadotropin-releasing hormone $(\mathrm{GnRH})$ system of the ewe: changes in synaptic inputs onto GnRH neurons. Endocrinology. 138:1240-50. 


\section{Curriculum Vita}

\section{Van Lee Adams}

Date and Place of Birth:

May 15, 1977. Dearborn, MI.

Education:

Bachelors of Art in Biology. West Virginia University, Morgantown, WV. 1999. 